\title{
Karadeniz'de hamsi (Engraulis encrasicolus) popülasyon dinamiği üzerine yapıımış çalışmaların (1985-2015) balıkçılık yönetimi açısından değerlendirilmesi
}

\section{Evaluation of anchovy (Engraulis encrasicolus) population dynamics studies (1985-2015) in terms of fisheries management in the Black Sea}

\author{
Sabri Bilgin* • Çetin Sümer • Serdar Bektaş • Hasan Hüseyin Satılmış • Recep Bircan \\ Sinop Üniversitesi, Su Ürünleri Fakültesi, TR57000, Sinop \\ *Corresponding author: sbrbilgin@hotmail.com
}

How to cite this paper:

Bilgin,S., Sümer, Ç., Bektaş, S., Satılmış, H.H. \& Bircan, R. (2016). Evaluation of anchovy (Engraulis encrasicolus) population dynamics studies (1985-2015) in terms of fisheries management in the Black Sea (in Turkish with English abstract). Ege Journal of Fisheries and Aquatic Sciences, 33(2): 169-.182.

doi: 10.12714/egejfas.2016.33.2.12

\begin{abstract}
Öz: : Bu çalışmada, hamsi (Engraulis encrasicolus) üzerine 1985 yılından günümüze son 30 yılda yapılan popülasyon dinamiği çalışmalarından elde edilen sonuçlar değerlendirimiş ve Karadeniz'de hamsi balıkçılık yönetim sisteminin olușturulmasına katkı sağlamak amaçlanmışıır. Araştırmalarda sunulan av kompozisyonu, büyüme parametreleri, yaşlardaki ortalama boy değerleri, genel ortalama boy değerleri, ölüm oranları ve işletme oranları av sezonlarına ve beş yıllık periyotlara göre değerlendirilmiş̧tir. Cinsi olgunluğa ulaşmamış sıfır yaşındaki bireylerin av içerisindeki oranı ortalama \%27,4 $\pm 3,6$ ( $n=26$ çalışma) olup, bu oran 1985 - 1990

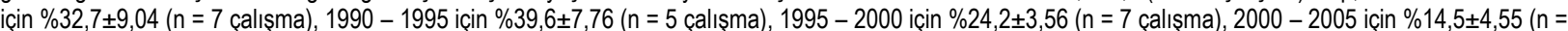
5 çalışma) ve $2005-2010$ için ise \%22,1 $21,1(n=2$ çalışma) şeklinde tespit edilmiştir. Sıfır yaşındaki bireylerin beş ylllık dönemlerdeki oranları arasındaki istatistiki fark önemsiz bulunmustur (one-way ANOVA, $P=0,2256)$. von Bertalanffy büyüme denklemi $(V B B D)$ parametrelerinden asimptotik boy $(L \infty)$ değeri 14,1 $-23,5 \mathrm{~cm}$ arasında (ortalama: $17,0 \pm 0,38 \mathrm{~cm}$ ), büyüme katsayıs (K) değeri ise $0,139-0,920 \mathrm{yll}-1$ arasında (ortalama: $0,331 \pm 0,031$ yıl-1) tespit edilmiştir. VBBD $L t=17,0 \pm 0,4(1-e-0,331 \pm 0,031$ ( $t+2,344 \pm 0,233)$ şeklinde $(n=26$ çalışma) hesaplanmışıı. L $\infty$ ve $K$ değerleri arasında $K=1105,3 L \infty-2,8958(r 2=0,6224, n=$ 26) şeklinde $(P<0,05)$, doğal ölüm oranı $(M)$ ile $K$ arasında ise $M=0,7171 K 0,3073(r 2=0,2982 ; n=26)$ șeklinde $(P<0,05)$ bir ilişki tespit edilmiştir. Bu denklemlerin regresyon katsayıları istatistiki olarak sıfırdan farklı bulunmuştur $(P<0,05)$. Hamsinin, L $\infty$ ve Lmaximum boy değerinin \%60-70'lik oranına bir yaşındayken hızı bir sekilde büyüyerek ulaștı̆̆ı tespit edilmiștir. Hamsinin yıllık ölüm oranını (Z), balıkçılık ölüm oranının (F) forse ettiği ve işletme oranın (E) ise 1985 - 1990 döneminden 2000 - 2005 dönemine kadar sürekli bir artış gösterdiği ve optimum değerin üzerinde olduğu ( $E>0,5 ; F>M)$ belirlenmiştir. Hamsi stokunun devamlılı̆ı ve en yüksek ürünü elde etmek için yıllık av miktarı ve av çabasının kontrol altına alınması, hamsi stok belirleme çalışmaları neticesinde kota uygulamasına geçilmesi ve Karadeniz'de hamsi balıkçıllı yönetim sisteminin oluşturulması önerilmiştir.
\end{abstract}

Anahtar kelimeler: Yaş, büyüme, ölüm oranları, balıkçlık yönetimi, Karadeniz, Türkiye

Abstract: In this study, the result on population dynamics of European anchovy (Engraulis encrasicolus) were evaluated from the present to the past 30 years in the Black Sea and is intended to contribute to the creation of the Black Sea anchovy fishery management system. In studies presented catch composition, growth parameters, the average length values in ages, the mean length values in general, mortality rates and exploration rates were evaluated in the fishing seasons and five-years periods. 0 years of age composition of individuals not reached sexual maturity was estimated as $27.4 \pm 3.6 \%$ ( $n=26$ studies), and this ratio was calculated as $32.7 \pm 9.04 \%$ for $1985-1990$ period ( $n=7$ studies), $39.6 \pm 7.76 \%$ for $1990-1995$ ( $n=5$ studies), $24.2 \pm 3.56 \%$ for $1995-2000$ ( $n=7$ studies), $14.5 \pm 4.55 \%$ for $2000-2005$ ( $n=5$ studies) and $22.1 \pm 21.1 \%$ for $2005-2010(n=2$ studies). Zero-year-old age composition was not significantly difference in the five-years periods (one-way ANOVA; $P>0.05$ ). The von Bertalanffy growth function (VBGF) parameters; asymptotic length $(L \infty)$ values were ranged between 14.1 $-23.5 \mathrm{~cm}$ (mean: $17.0 \pm 0.38 \mathrm{~cm}$ ) and brody growth coefficient $(\mathrm{K})$ values were ranged between $0.139-0920$ year- 1 (mean: $0.331 \pm 0.031$ year-1). The VBGF was calculated as $L t=17.0 \pm 0.4(1-\mathrm{e}-0.331 \pm 0.031(t+2.344 \pm 0.233)(\mathrm{n}=26$ studies $)$. A relationship between $\mathrm{L} \infty$ and $\mathrm{K}$ values was calculated as $\mathrm{K}=1105.3 \mathrm{~L} \infty-2.8958$ $(r 2=0.6224, n=26)$. The relationship between natural mortality ratio $(M)$ and $K$ values was determined as $M=0.7171 \mathrm{~K} 0.3073(r 2=0.2982 ; n=26)$. Regression coefficients of this equations were found to be statistically different from zero $(P<0.05)$. Anchovy grew quickly reach at 1 age of $60-70 \%$ in the value of $L \infty$ and Lmaximum length values. The instantaneous mortality ratio $(Z)$ of anchovy was designated by fishing mortality ratio ( $F)$. The exploration ratio $(E)$ consistently show an increase from $1985-1990$ period to $2000-2005$ period and it was determined as above the optimum value $(E>0.5 ; F>M)$. It has been proposed the creation of the Black Sea anchovy fishery management system for sustainable anchovy fisheries in the Black sea.

Keywords: Age, growth, mortality ratios, fisheries management, Black Sea, Turkey 


\section{GíRiş}

Hamsi (Engraulis encrasicolus Linnaeus, 1758) ülkemizde en çok avlanan balık türü olup, hızlı büyüyen, kısa ömürlü ve çevresel faktörlerden çok fazla etkilenen çevresel duyarlılığ yüksek bir türdür (Prodanov vd., 1997; Kideys vd., 1999; Bilgin, 2006; Bat vd., 2007). Karadeniz'de 3-4 yaşına kadar yaşamakta (Prodanov vd., 1997), yaklaşık 1 yaşında ve $9 \mathrm{~cm}$ boyda iken cinsi olgunluğa ulaşmaktadır (Kayalı, 1998).

Hamsinin Karadeniz'de yumurtlaması, termoklin tabakasının üstünde ve $0-20 \mathrm{~m}$ derinlikte, su sıcaklığının $15^{\circ} \mathrm{C}$ civarında olduğu nisan - mayıs ayında başlar, yaz boyunca yoğun bir şekilde yumurtlar ve su sıcaklığının $25^{\circ} \mathrm{C}$ civarında olduğu eylül ayının sonuna kadar yumurtlama faaliyeti devam eder (Lisovenko ve Andrianov, 1996; Kideys vd., 1999; Satılmış vd., 2003). Cinsi olguluğa ulaşmış bir dişi bireyin üreme sezonu boyuca 5000 - 40000 civarında yumurtayı 4-5 batında yumurtladığı rapor edilmesine rağmen (Slastenenko, 1955/1956), Karadeniz'de yapılan bir çalışmada bu oran yaklaşık 50 batında ve 138000-230000 civarında bildirilmiştir (Lisovenko ve Andrianov, 1996). Yani hamsi yaklaşık 5 ay süreyle günde 2-3 kez yumurtlama özelliği göstermektedir.

Avlanan balık stokları, büyüme ve üreme ile artmakta, balıkçılık kaynaklı ölümler ve doğal ölümlerle ise azalmaktadır (Erkoyuncu, 1995; Avşar, 2005). Türkiye'de hamsi balıkçılık yönetimine veri sağlamak amacıyla; popülasyon dinamiği kapsamında 1985 yılından günümüze son 30 yılda büyüme, üreme ve ölüm oranlarını içeren bir çok çalışma yapılmıştır. Söz konusu çalışmalar tablo 1'de gösterilmiştir. Bu konuda bir derleme Bilgin (2006) tarafından 1985 - 2005 yılları arasını kapsayan dönemde hamsi için sunulmuş ve av sezonlarına göre von Bertalanffy büyüme denklemi (VBBD) parametreleri $(L \infty, K$ ve t0), balıkçılık $(F)$ ve doğal ölüm oranı $(M)$ ve işletme oranı (E) gibi parametrelerin değişimi 20 yıllık periyot için değerlendirilmiştir.

Bu çalışmada 1985'den 2015 yılına kadar Karadeniz'de Türkiye sularından örneklenerek yapıımış popülasyon dinamiği çalışmaları incelenerek, hamsinin yaş kompozisyonu, boy kompozisyonu, yaşlardaki ortalama boy değerleri, von Bertalanffy büyüme denklemi (VBBD) parametreleri ve ölüm oranının değişimi Karadeniz'de sürdürülebilir bir hamsi balıkçılığı yönetiminin oluşturulmasına katkı sağlamak amacıyla incelenmiştir. Sonuçlar av sezonlarına ve 5'er yıllık periyotlar 1985 - 1990, 1990 - 1995, 1995 - 2000, 2000 2005, 2005 - 2010 halinde değerlendirilerek, parametrelerin birbirleriyle ilişkileri matematiksel olarak formulize edilmiş ve yorumlanmıştır.

\section{MATERYAL VE YÖNTEM}

Bu çalışmada, Tablo 1'de sunulan ve 1985 - 2015 yılları arası Türkiye'nin Karadeniz kıyılarında yapılan popülasyon dinamiği çalışmalarının sonuçları değerlendirilmiştir. Bu kapsamda; çalışmalardaki yaş kompozisyonu, yaşlardaki ortalama boy, von Bertalanffy büyüme denklemi (VBBD) parametreleri, boy ağırlık ilişkisi, toplam ölüm oranı (Z), doğal ölüm oranı $(M)$, balıkçılık ölüm oranı $(F)$ ve işletme oranı $(E)$ değerlerinin av sezonlarına ve 5 yıllık periyotlara göre aritmetik ortalama ve standart hataları ile iki değişken (örneğin $L \infty$ ve K) arasındaki regresyon denklemleri ile korelasyon katsayıları belirlenmiştir. İkiden fazla değişkenli parametrenin ortalamaları arasındaki fark tek yönlü varyans analizi ile (one-way ANOVA) PAST versiyon 2.14 programı (Hammer vd., 2001) kullanılarak test edilmiştir.

Korelasyon katsayısının sıfırdan farklı olup olmadığı t-testi ile aşağıdaki eşitliğe göre (Eşitlik 1) test edilmiştir (Snedecor and Cochran, 1989).

$$
t=\frac{r \sqrt{n-2}}{\sqrt{1-r^{2}}}
$$

burada $n$ örnek sayısını ifade etmektedir. Hesaplanan $t$ değeri (n-2) serbestlik derecesinde tablo t değerinden büyükse fark istatistiki olarak önemlidir.

Sezonsal büyümenin belirlenmesinde Bilgin vd., (2013) tarafından yayınlanan makale verileri kullanılmış ve söz konusu makaledeki veriler üzerinden ömür uzunluğu Taylor (1958) tarafından önerilen aşağıdaki eşitliğe göre (Eşitlik 2) hesaplanmıştır.

$$
A_{95}=t_{0}+\frac{2,966}{K}
$$

burada A95 ömür uzunluğunu (yıl), K brody büyüme katsayısını (yıl-1) ve to ise hamsinin yumurtadan çımmadan önceki kuramsal yaşını (yıl) ifade etmektedir.

Dişi ve erkekler için sezonsal VBBD eğrisi grafiği Bilgin vd., (2013) tarafından yayımlanan mevsimsel VBBD parametreleri $(\mathrm{L} \infty, \mathrm{K}, \mathrm{t0}, \mathrm{C}$ ve ts) sonuçları kullanılarak Somers (1988) tarafından önerilen aşağıdaki eşitliğe göre (Eşitlik 3) çizilmiştir.

$\left.L_{t}=L_{\infty}\left[1-e^{\left[-K\left(t-t_{o}\right)-\left(C \frac{K}{2 \pi}\right) \sin 2 \pi\left(t-t_{S}\right)+\left(C \frac{K}{2 \pi}\right) \sin 2 \pi\left(t_{o}-t_{S}\right)\right.}\right]\right](3)$

burada $L \infty, K$ ve to standart VBBD parametreleri, C: sinusoidal salınım genliği, ts ise sinusoidal salınım başlangıcı olup kış büyüme noktasının (WP $=$ ts $+0,5)$ hesaplanmasında kullanılan parametredir. 
Tablo 1. Son 30 yılda (1985 ve 2015 arası) Türkiye'nin Karadeniz kıyılarında yapılan popülasyon dinamiği çalışmaları. +: veri var anlamındadır. Koyu olan kareler ise veri yok anlamındadır. YK: Yaş Kompozisyonu (\%), YOB: Yaşlardaki Ortalama Boy (cm), VBBD: von Bertalanffy Büyüme Denklemi Parametreleri, BAi: Boy Ağırık Ilişkisi, ÖO: Ölüm Oranları. 0, I, II, III: yaşlardaki \% oranları, L0, L1, L2, L3: yaşlardaki ortalama boyları, L $\infty$, K, t0: von Bertalanffy Büyüme denklemi parametreleri, a ve b: boy ağırlık ilişkisi parametreleri, Lort: ortalama boy, Z: toplam ölüm oranı, M: doğal ölüm oranı, F: balıkçılık ölüm oranı, E: işletme oranıdır.

Table 1. Population dynamics studies conducted in the last 30 years (between 1985 and 2015) in the Turkish Black Sea coasts. + there are data. Dark squares: no data, AC: Age composition, MLA: mean length at ages, VDGF: von Bertalanffy growth function parameters, WLRs: weight-length relationships, MR: mortality ratios, 0, I, II, III: percentages at ages, LO, L1, L2, L3: mean length at ages, L $\infty, \mathrm{K}$, t0: VDGF parameters, a and b: weight - length relationships parameters, Lmean: mean length, $\mathrm{Z}$ : instantaneous mortality ratio, $\mathrm{M}$ : natural mortality ratio, $\mathrm{F}$ : fishing mortality ratio, $\mathrm{E}$ : exploration ratio

\begin{tabular}{|c|c|c|c|c|c|c|c|c|c|c|c|c|c|c|c|c|c|c|c|c|}
\hline \multirow{2}{*}{ Sezon } & \multicolumn{4}{|c|}{ YK } & \multicolumn{4}{|c|}{ YOB } & \multicolumn{3}{|c|}{ VBBD } & \multicolumn{2}{|c|}{ BAI } & \multicolumn{3}{|c|}{ Öo } & \multirow[b]{2}{*}{$E$} & \multirow[b]{2}{*}{$\mathrm{M} / \mathrm{K}$} & \multirow[b]{2}{*}{ Lort } & \multirow{2}{*}{ Lit. } \\
\hline & 0 & $I$ & II & III & $L_{0}$ & $L_{1}$ & $L_{2}$ & $\mathrm{~L}_{3}$ & $L_{\infty}$ & $K$ & $t_{0}$ & $a$ & b & Z & $M$ & $F$ & & & & \\
\hline $1985-86$ & + & + & + & + & + & + & + & + & + & + & + & + & + & + & + & + & + & + & + & [1] \\
\hline $1986-87$ & + & + & + & + & + & + & + & + & + & + & + & + & + & + & + & + & + & + & + & [2] \\
\hline 1987-88 & + & + & + & + & & 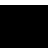 & 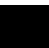 & 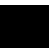 & + & + & + & + & + & + & + & + & + & + & & [3] \\
\hline 1987-88 & + & + & + & + & + & + & + & + & + & + & + & & 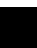 & + & + & + & + & + & + & [4] \\
\hline 1988-89 & + & + & + & + & + & + & + & + & + & + & + & & & + & + & + & + & + & + & [4] \\
\hline 1988-89 & + & + & + & + & + & + & + & + & + & + & + & + & + & + & + & + & + & + & + & [5] \\
\hline 1989-90 & + & + & + & + & + & + & + & + & + & + & + & + & + & + & + & + & + & + & + & [6] \\
\hline 1990-91 & + & + & + & 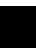 & + & + & + & & + & + & + & + & + & + & + & + & + & + & + & [7] \\
\hline 1991-92 & + & + & + & + & + & + & + & + & + & + & + & + & + & + & + & + & + & + & + & [8] \\
\hline 1992-93 & + & + & + & + & + & + & + & + & + & + & + & + & + & + & + & + & + & + & + & [9] \\
\hline 1993-94 & + & + & + & + & + & + & + & + & + & + & + & + & + & + & + & + & + & + & + & [10] \\
\hline 1994-95 & + & + & + & + & + & + & + & + & + & + & + & + & + & + & + & + & + & + & + & [11] \\
\hline 1995-96 & + & + & + & + & 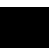 & 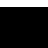 & 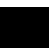 & 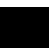 & + & + & + & + & + & + & + & + & + & + & . & [12] \\
\hline 1996-97 & + & + & + & . & + & + & + & & + & + & + & + & + & + & + & + & + & + & + & [13] \\
\hline 1996-97 & + & + & + & + & + & + & + & + & + & + & + & + & + & + & + & + & + & + & + & [14] \\
\hline 1997-98 & + & + & + & + & + & + & + & + & + & + & + & + & + & + & + & + & + & + & + & [14] \\
\hline 1997-98 & + & + & + & + & + & + & + & + & + & + & + & + & + & + & + & + & + & + & + & [15] \\
\hline 1998-99 & + & + & + & + & + & + & + & + & + & + & + & + & + & + & + & + & + & + & + & [16] \\
\hline 1999-00 & + & + & + & + & + & + & + & + & + & + & + & + & + & + & + & + & + & + & + & [16] \\
\hline $2000-01$ & + & + & + & + & + & + & + & + & + & + & + & + & + & + & + & + & + & + & + & [17] \\
\hline 2001-02 & + & + & + & + & + & + & + & + & + & + & + & + & + & + & + & + & + & + & + & [17] \\
\hline 2002-03 & + & + & + & + & + & + & + & + & + & + & + & + & + & + & + & + & + & + & + & [17] \\
\hline 2004-05 & + & + & + & + & + & + & + & + & + & + & + & & 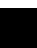 & + & + & + & + & + & + & [18] \\
\hline 2004-05 & + & + & + & + & + & + & + & + & + & + & + & + & + & + & + & + & + & + & + & [19] \\
\hline 2005-06 & + & + & + & + & + & + & + & + & + & + & + & + & + & + & + & + & + & + & + & [19] \\
\hline 2009-10 & & & & & & & & & & & & & & & & & & & + & [20] \\
\hline 2010-11 & + & + & + & + & + & + & + & + & + & + & + & + & + & + & + & + & + & + & + & [21] \\
\hline
\end{tabular}

[1]: Erkoyuncu ve Özdamar (1989), [2]: Karaçam ve Düzgüneş (1990), [3]: Düzgüneş ve Karaçam (1989), [4]: Özdamar vd. (1994), [5]: Ünsal (1989), [6]: Okur (1990), Mutlu (2000)'den, [7]: Genç ve Başar (1991), Mutlu (2000)'den, [8]: Genç ve Başar (1992), Mutlu (2000)'den, [9]: Genç ve Başar (1993), Mutlu (2000)'den [10]: Mutlu (1994), [11]: Özdamar vd. (1995), [12]: Mutlu (1996), Mutlu (2000)'den, [13]: Kayalı (1998), [14]: Mutlu (2000), [15]: Gözler ve Çiloğlu (1998), [16]: Samsun vd., (2004), [17]: Samsun vd. (2006), [18]: Bilgin vd. (2006), [19]: Şahin vd., (2008), [20]: Genç vd. (2010), [21]: Sağlam ve Sağlam (2013). 


\section{BULGULAR}

\section{Yaş kompozisyonu}

Av sezonlarına göre hamsi üzerine yapılmış 26 çalışmanın yaş kompozisyonunun değişim grafiği şekil 1'de sunulmuştur. Hamsinin yaş kompozisyonunda av sezonlarına göre önemli dalgalanmalar görülmüştür.

Diğer taraftan, avlanan hamsi balı̆ı̆ının yaş kompozisyonu bütün olarak değerlendirildiğinde (Şekil 2), avcılığın 1 yaşındaki bireylerin üzerinde yoğunlaşıı̆̆ (ortalama: $\% 42,3 \pm 3,3 ;$ ), avlanan balıkların kompozisyonunu bir yaşındaki bireylerden sonra sıfır yaş ( $\% 27,4 \pm 3,6 ;)$, iki yaş (\%25 $\% 3,3 ;)$ ve az miktarda da üç yaşındaki $(\% 6 \pm 1,2)$ balıkların oluşturduğu tespit edilmiştir. Yaş kompozisyonu sonuçları beş yıllık dönemler halinde (1985 - 1990), (1990 - 1995), (1995 - 2000), (2000 $2005)$ ve $(2005-2010)$ şekil 3'te sunulmuştur. SIfır yaşındaki bireylerin \% oranları $(1985-1990)$ için $\% 32,7 \pm 9,04(n=7$ çalışma), $(1990$ - 1995) için \%39,6 $\pm 7,76$ ( $n=5$ çalışma), (1995 -2000 ) için $\% 24,2 \pm 3,56$ ( $n=7$ çalışma), $(2000-2005)$ için $\% 14,5 \pm 4,55$ ( $n=5$ çallşma) ve $(2005-2010)$ için ise $\% 22,1 \pm 21,1(n=2$ çalışma) şeklinde tespit edilmiştir. SIfır yaşındaki bireylerin beş yillık dönemlerdeki oranları arasında istatistiksel olarak fark önemsiz bulunmuştur (one-way ANOVA, $P=0,2256)$.

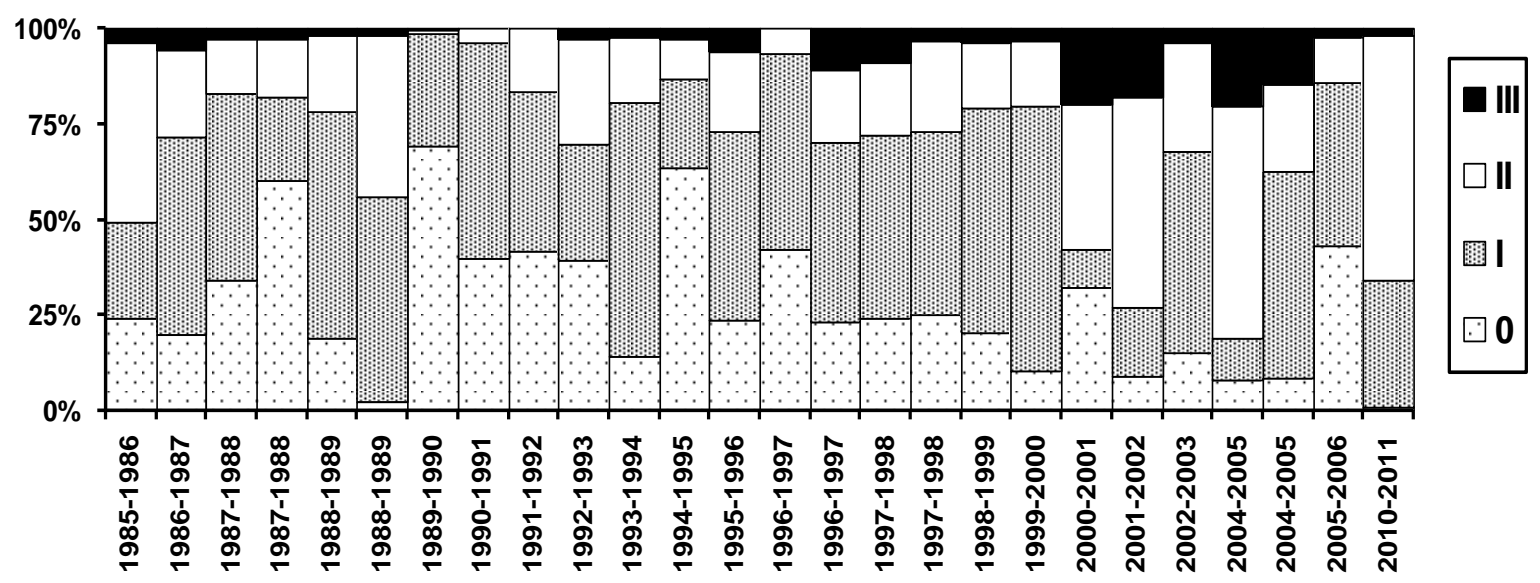

Şekil 1. Türkiye sularında avlanan (1985 - 2011) hamsi balığının av sezonlarına göre yaş kompozisyonu

Figure 1. Age composition in fishing seasons of anchovy fished in the waters of Turkey (1985 - 2011)

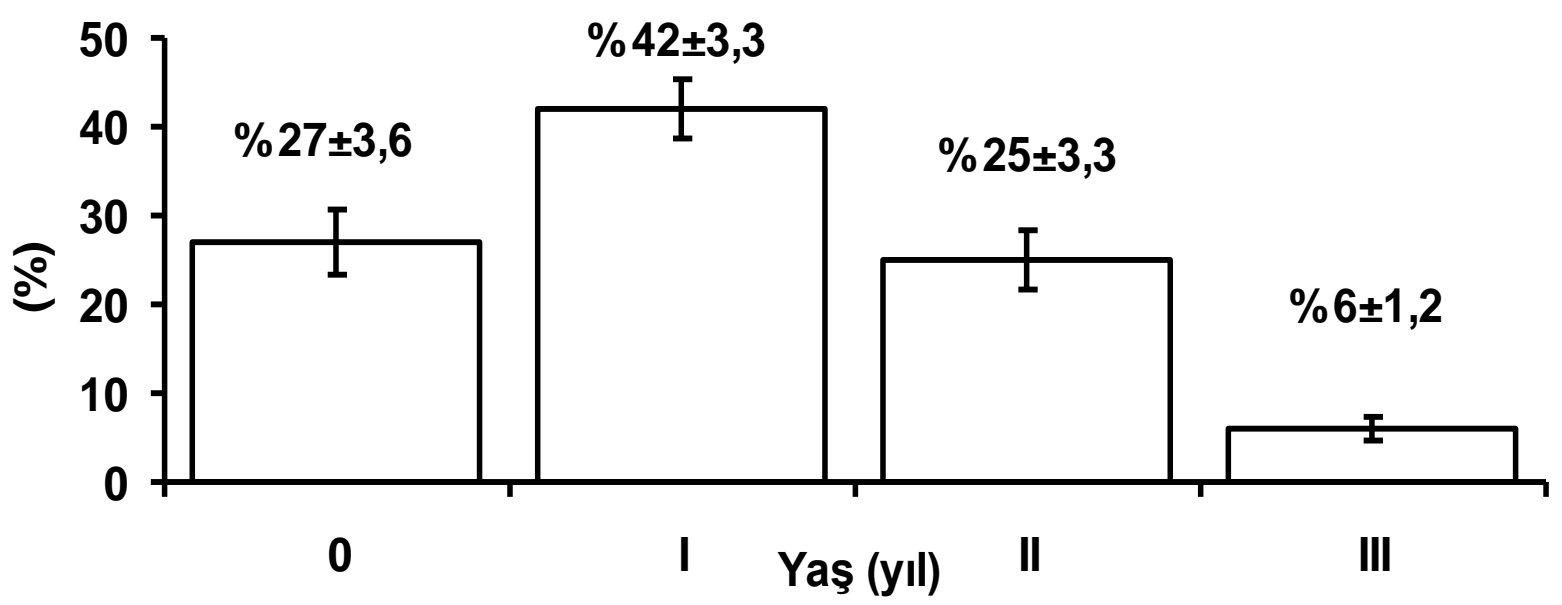

Şekil 2. Türkiye sularında avlanan (1985 - 2010) hamsi balığının genel yaş kompozisyonu

Figure 2. General age composition of anchovy fished in the waters of Turkey (1985 - 2010) 
(7)

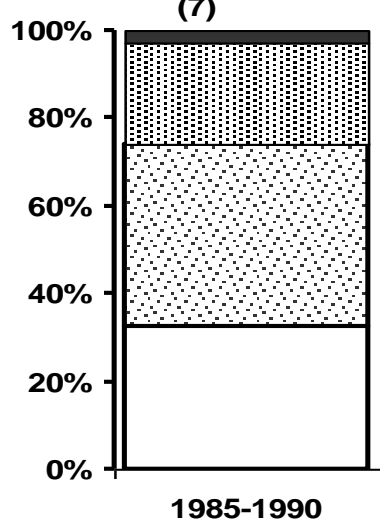

(5)

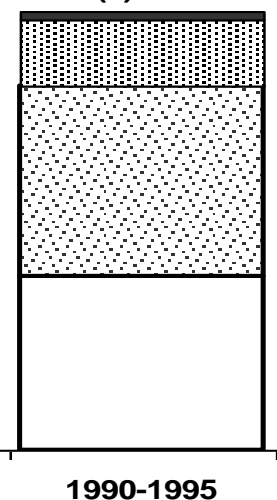

(7)

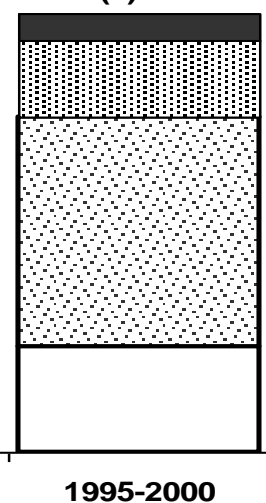

(5)

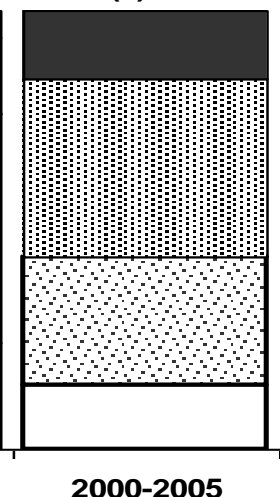

(2)

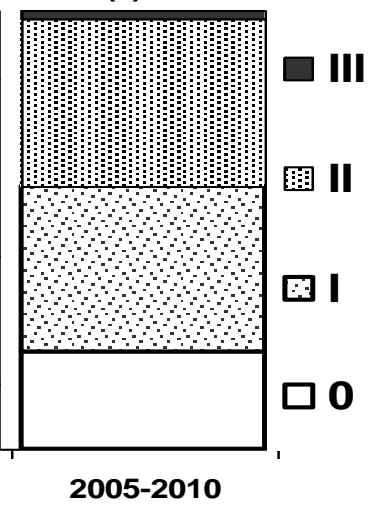

Şekil 3. Türkiye sularında avlanan hamsi balığının beş yıllık dönemlerde yaş kompozisyonu. Parantez içerisindeki rakamlar beş yıllık dönemlerde araştırma sayısını göstermektedir

Figure 3. Age composition in the five years periods of anchovy fished in the waters of Turkey. The numbers in parentheses indicate the number of researches in the five years periods

\section{Yaşlardaki ortalama boy}

Av sezonlarına göre yaşlardaki ortalama boyların değişimi şekil 4'te gösterilmiştir. Av sezonlarına göre hesaplanan ortalama boy değeri $8,5-11,6 \mathrm{~cm}$ arasında olup, avlanan balıkların ortalama boyu bir yaşındaki balıkların ortalama boyuna (8,8 - 11,1 cm arasında) yakın bir dalgalanma göstermiştir.

Yaşlardaki ortalama boy (1985 - 1990), (1990 - 1995), (1995 - 2000), (2000 - 2005) ve (2005 - 2010) periyotları için değerlendirildiğinde (Şekil 5), sırasıyla sıfır yaşında: $8,5 \pm 0,17$ $\mathrm{cm}, 8,1 \pm 0,15 \mathrm{~cm}, 8,3 \pm 0,16 \mathrm{~cm}, 8,5 \pm 0,16 \mathrm{~cm}$ ve $7,8 \pm 0,62 \mathrm{~cm}$, bir yaşında: $10,3 \pm 0,11 \mathrm{~cm}, 10,1 \pm 0,34 \mathrm{~cm}, 10,6 \pm 0,13 \mathrm{~cm}$, $10,3 \pm 0,20 \mathrm{~cm}$ ve $10,3 \pm 0,18 \mathrm{~cm}$, iki yaşında: $12,5 \pm 0,29 \mathrm{~cm}$,
$12,1 \pm 0,19 \mathrm{~cm}, 12,3 \pm 0,08 \mathrm{~cm}, 11,7 \pm 0,16 \mathrm{~cm}, 12,2 \pm 0,07 \mathrm{~cm}$ ve üç yaşında ise $13,4 \pm 0,23 \mathrm{~cm}, 13,2 \pm 0,16 \mathrm{~cm}, 13,3 \pm 0,06 \mathrm{~cm}$, $13,1 \pm 0,23 \mathrm{~cm}, 13,3 \pm 0,52 \mathrm{~cm}$ olarak hesaplanmıştı. Beş yıllık periyotlarda hesaplanan ortalama boylar arasındaki fark (şekil 7) istatistiki olarak önemsiz bulunmuştur (One-way ANOVA, $P$ $=0,105)$.

Avlanan hamsi balığının yaşlardaki ortalama boy değerleri sezonlara bakılmaksızın bir bütün halinde şekil 6'da sunulmuştur. Yaşlardaki ortala boy değerleri, sıfır yaşında $8,3 \pm 0,1 \mathrm{~cm}$ ( $n=24$ çalışma), bir yaşında $10,3 \pm 0,1 \mathrm{~cm}(n=24$ çalışma), iki yaşında $12,1 \pm 0,1 \mathrm{~cm}(\mathrm{n}=24$ çalışma) ve üç yaşında ise $13,3 \pm 0,1 \mathrm{~cm} \quad(\mathrm{n}=22$ çalışma) olarak hesaplanmıştır.

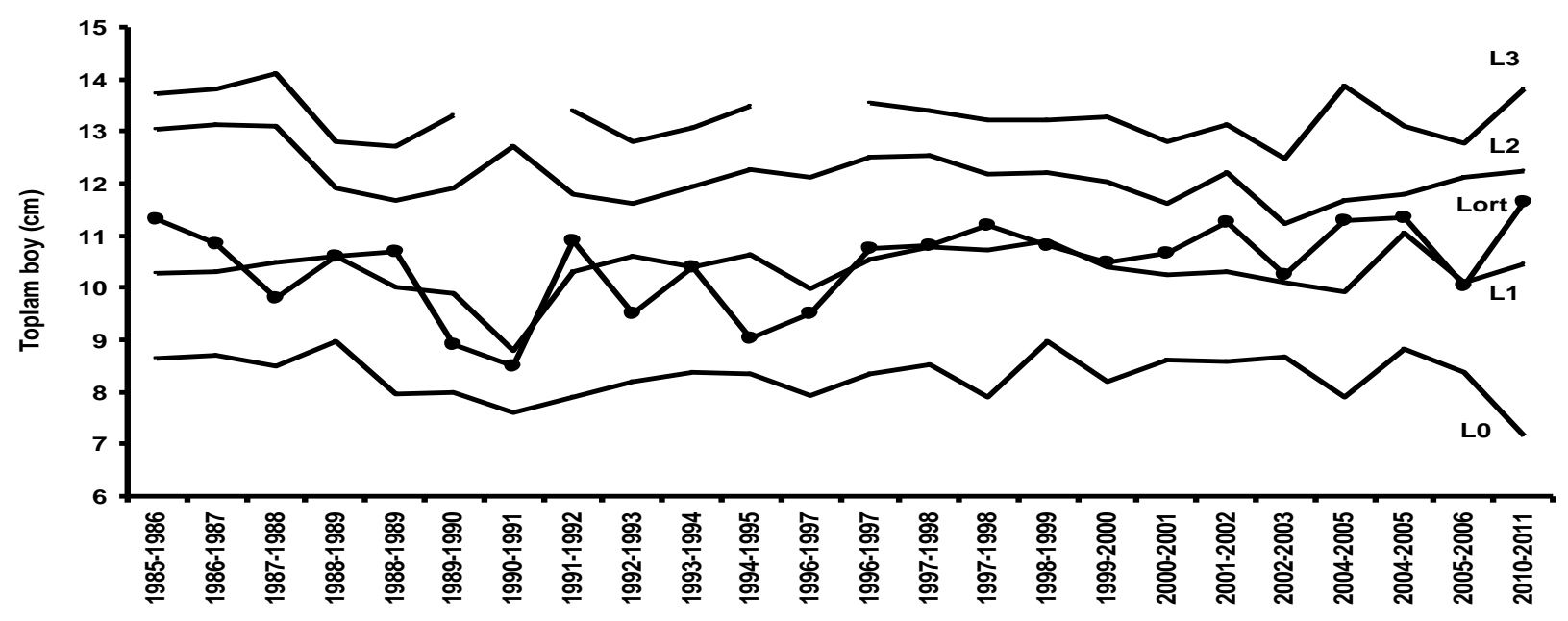

Şekil 4. Türkiye sularında avlanan hamsi balığının yaşlardaki ortalama boylarının değişimi. L0,1,2,3: yaşlardaki ortalama boylar, Lort: ortalama boy Figure 4. Changes of mean length at the ages of anchovy caught in waters of Turkey. L0,1,2,3: mean length in ages, Lmean: mean length 


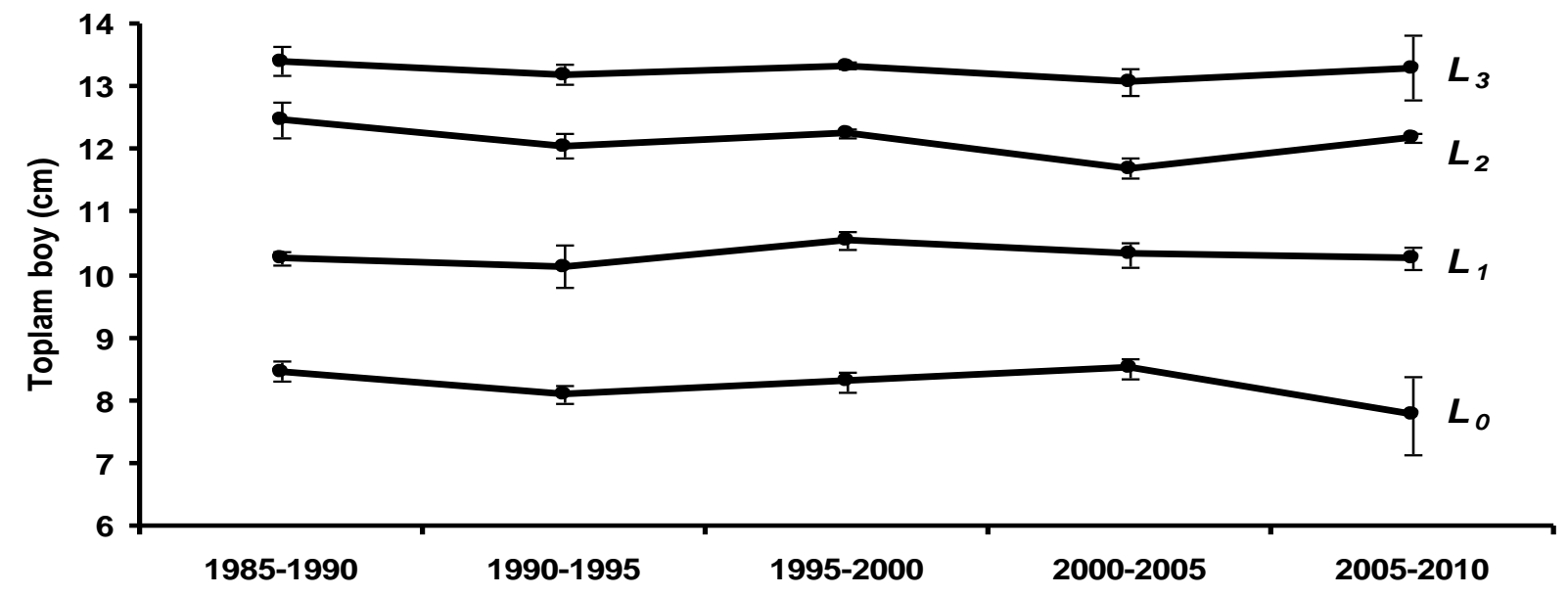

Şekil 5. Türkiye sularında avlanan hamsi balığının beş yıllık dönemlerde yaşlardaki ortalama boylarının değişimi. Dikey çubuklar standart sapmayı göstermektedir Figure 5. Changes in the mean length at the ages in the five years periods of anchovy caught in waters of Turkey age five years

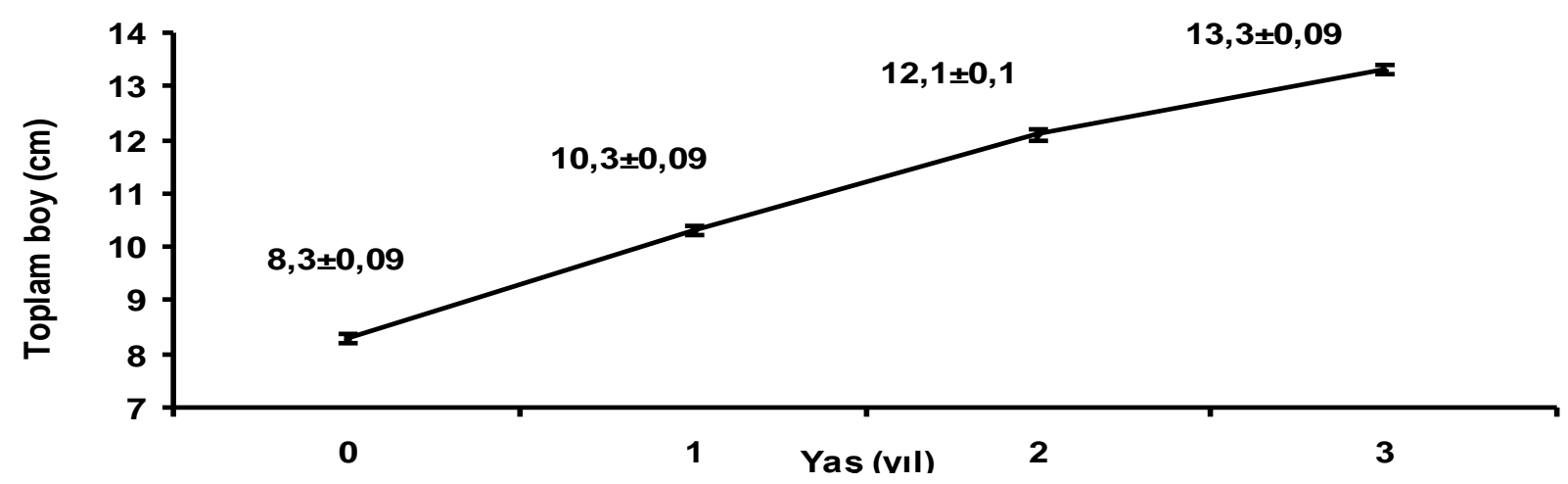

Şekil 6. Türkiye sularında avlanan hamsi balı̆ının yaşlardaki ortalama toplam boy değerleri. Dikey çubuklar standart sapmayı göstermektedir Figure 6. Mean total length values at the ages of anchovy caught in waters of Turkey. Vertical bars indicate standard deviation

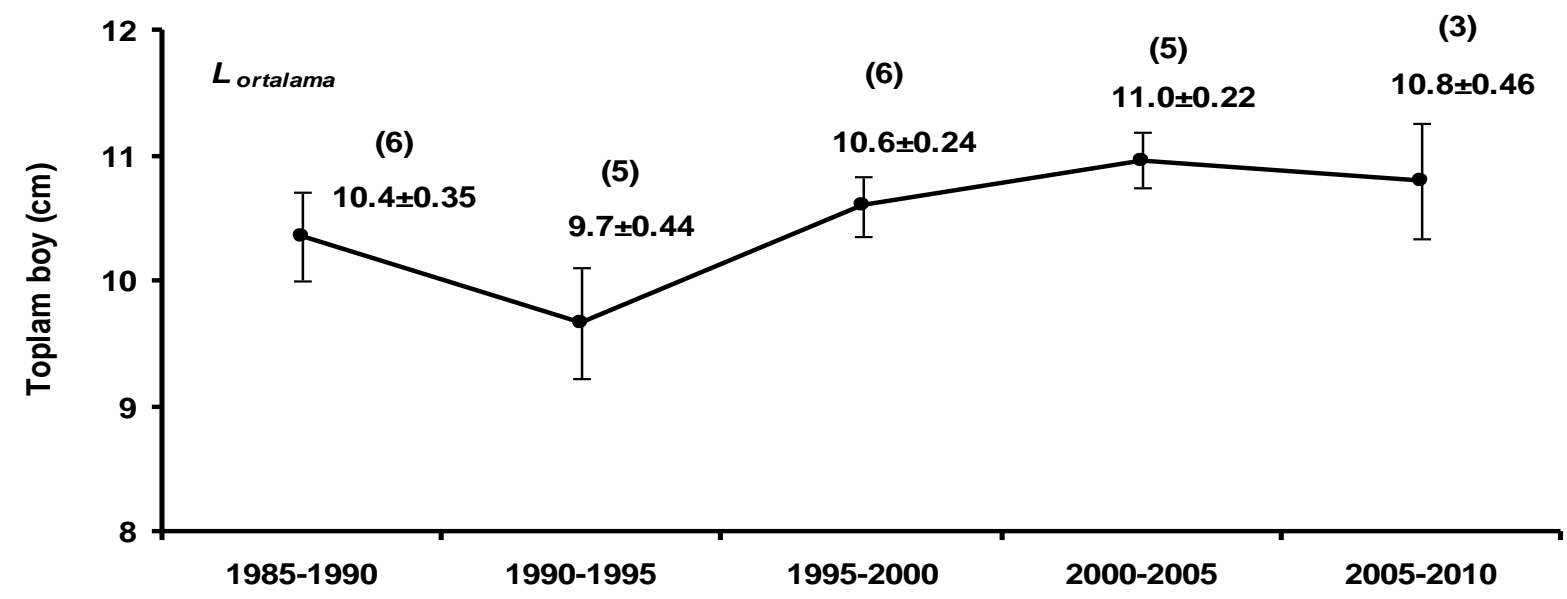

Şekil 7. Türkiye sularında avlanan hamsi balı̆ı̆ın ortalama boyunun (Lortalama, $\mathrm{cm}$ ) beş yıllık dönemlerdeki değişimi

Figure 7. Changes of mean length (Lmean, $\mathrm{Cm}$ ) in the five years periods of anchovy caught in waters of Turkey 
Bir yaşındaki bireylerin $L \infty$ ve Lmaximum boy değerlerine ulaşma oranları

Av sezonlarına göre hamsi üzerine yapılmış çalışmaların bir yaşındaki bireylerin $L \infty$ ve Lmaximum boy değerlerine ulaşma oranları (\% olarak) değişim grafiği şekil 8'de sunulmuştur.

Bir yaşındaki bireylerin ortalama boy değerlerinin $L_{\infty}$ değerine ulaşma oranının \%42,2 - \%69,7 arasında olduğu (ortalama: $\% 60,8 \pm 1,4)$, Lmaximum boy değerine ulaşma oranının ise $\% 61,1$ - \%77,6 arasında olduğu (ortalama: $\% 70,6 \pm 1,0$ ) tespit edilmiştir. Bu sonuçlar, hamsi balığının 1 yaşına hızı bir şekilde ulaştığını ve hızlı büyüme özelliği gösteren bir balık olduğunu göstermektedir. Ayrıca Karadeniz'de hamsi üzerine yapılan çalışmalar incelendiğinde, rapor edilen en uzun boylu hamsi, 1986 - 1987 av sezonunda Karaçam ve Düzgüneş (1990) tarafından ölçülen $16,9 \mathrm{~cm}$ uzunluğundaki değer olup, bu değer araştırmalarda rapor edilen en uzun boydur.
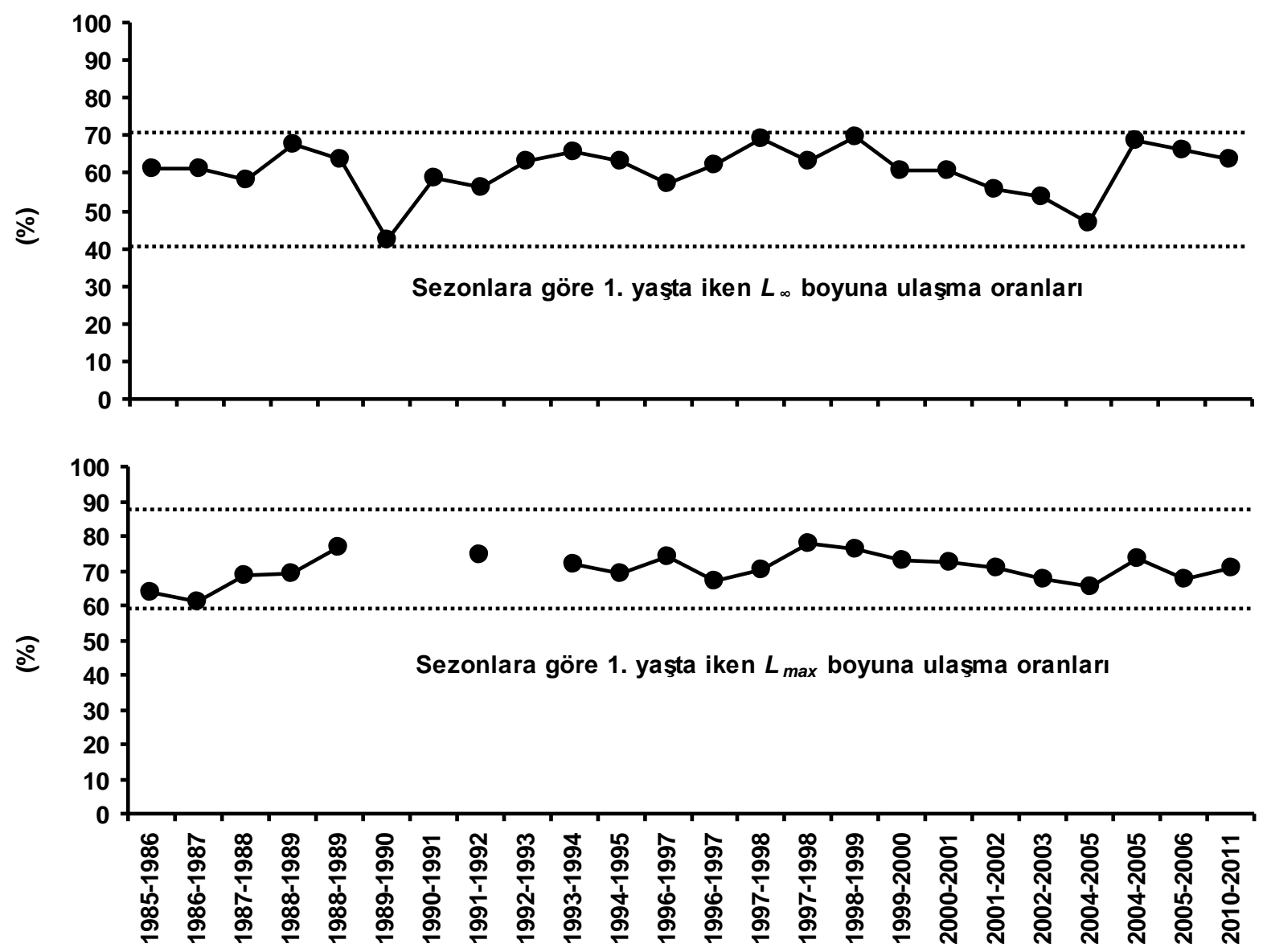

Şekil 8. Bir yaşındaki hamsi balığının sonuşmaz kuramsal uzunluğuna, $\mathrm{cm}(\mathrm{L} \infty)$ ve Lmaximum boy $(\mathrm{cm})$ değerlerine ulaşma oranları Figure 8. The proportion of reach to asymptotic $(\mathrm{L} \infty, \mathrm{cm})$ and maximum length $(\mathrm{Lmax}, \mathrm{cm})$ of one year old anchovy

\footnotetext{
Von-Bertalanffy büyüme denklemi (VBBD) $2.344 \pm 0,233$ yıl) olduğu belirlenmiştir. Tüm veriler parametreleri değerlendirildiğinde hamsi için VBBD $L t=17,0 \pm 0,4(1-$ e-

Av sezonlarına göre hamsi üzerine yapılmış 26 çalışmada hesaplanan VBBD parametreleri sonuçlarına göre $L \infty$ değerinin 14,1 - 23,5 cm (ortalama: $17,0 \pm 0,38 \mathrm{~cm}$ ) arasında, $\mathrm{K}$ değerinin 0,139-0,920 yıl-1 arasında (ortalama: 0,331 $\pm 0,031$ yıl-1) ve t0 değerinin ise $-6,145$ ve $-0,070$ arasında (ortalama: -

1985 - 1990 için ( $n=6$ çalışma): $L t=17,2 \pm 1,14$ (1 - e$0,371 \pm 0,095(\mathrm{t}+2,144 \pm 0,346))$ $0,331 \pm 0,031(t+2,344 \pm 0,233)$ şeklinde hesaplanmıştır.

Hamsi üzerine yapılmış çalışmalardan hesaplanan VBBD parametreleri beş yıllık dönemlerde değerlendirildiğinde ise VBBD formülü $L t=L \infty \pm$ Std. Hata $(1-e-K \pm$ Std. Hata (tt0 \pm Std. Hata)) formatında aşağıdaki şekilde hesaplanmıştır.

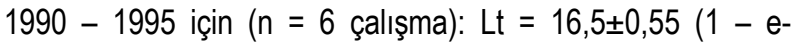
$0,403 \pm 0,067(t+1,383 \pm 0,480))$
} 
$1995-2000$ için $(n=7$ çalışma): Lt $=16,6 \pm 0,27$ ( 1 - e$0,313 \pm 0,019(t+2,766 \pm 0,570))$

$2000-2005$ için $(n=5$ çalışma): Lt $=18,3 \pm 0,88(1-\mathrm{e}-$ $0,219 \pm 0,022(t+2,957 \pm 0,284))$

$2000-2010$ için $(n=2$ çalışma): Lt $=15,8 \pm 0,55(1-\mathrm{e}-$ $0,355 \pm 0,071(\mathrm{t}+2,440 \pm 1,090))$

$1985-2010$ için ( $n=26$ çalışma) Lt $=17,0 \pm 0,40(1-\mathrm{e}-$ $0,331 \pm 0,031(t+2,344 \pm 0,233))$

\section{L $\infty$ ve K ilişkisi}

Av sezonlarına göre hamsi üzerine yapılmış 26 çalışmadan elde edilen $L \infty$ ve $K$ değerleri regresyona tabi tutulduğunda $K$ $=1105,3 \mathrm{~L} \infty-2,8958(\mathrm{r} 2=0,6224, \mathrm{n}=26, \mathrm{P}<0,05)$ şeklinde üssel bir ilişki tespit edilmiş olup (Şekil 9 ), $L \infty$ ve $K$ arasındaki korelasyon katsayısı istatistiksel olarak sıfırdan farklı hesaplanmıştır $(P<0,05)$.

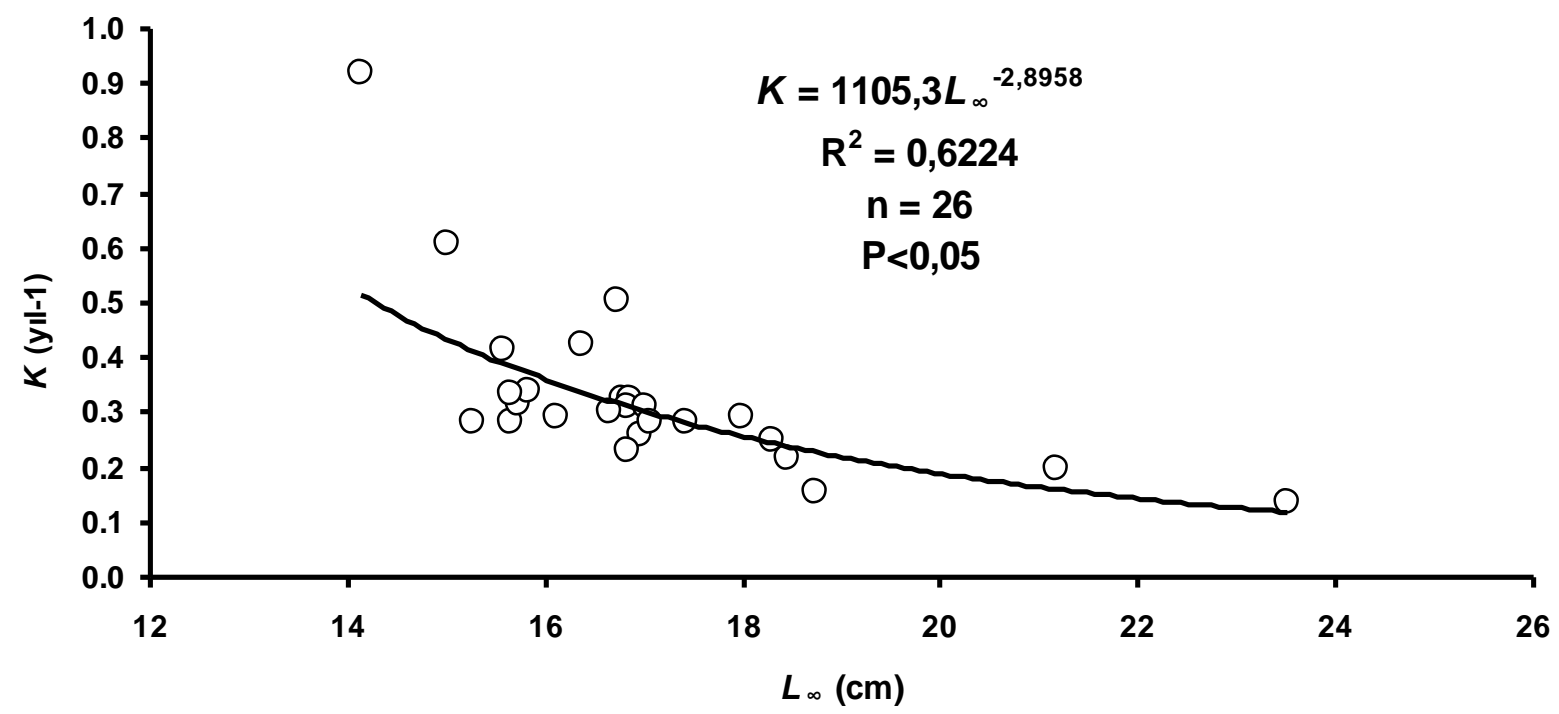

Şekil 9. Türkiye sularında avlanan hamsi balığının sonuşmaz kuramsal uzunluğu, $(\llcorner\infty, \mathrm{cm})$ ve Brody büyüme katsayısı $(K, y ı l-1)$ arasındaki ilişki Figure 9. Relationship of between asymptotic length $(\mathrm{L} \infty, \mathrm{cm})$ and brody growth coefficient $(K$, year- 1$)$ of anchovy caught in waters of Turkey

\section{Ölüm oranları ve işletme oranı}

Av sezonlarına göre hamsi üzerine yapıımış 26 çalışmalardan hesaplanan ölüm oranı parametreleri ( $Z$ = toplam ölüm oranı, $M$ = doğal ölüm oranı, $F=$ balıkçıık ölüm oranı) sonuçlarına göre balıkçılık ölüm oranıyla toplam ölüm oranının av sezonları boyunca benzer şekilde dalgalanmalar gösterdiği, işletme oranının ise iki çalışma sonucu hariç optimum seviyenin $(E=0,5)$ üzerinde olduğu belirlenmiştir (Şekil 10).

İşletme oranının beş yıllık dönemlerdeki sonuçları incelendiğinde (Şekil 11), 1985 - 1990 döneminden 2000 2005 dönemine kadar sürekli bir artış göstererek ortalama $E=$ $0,8 \pm 0,1$ seviyesine ulaştı̆̆ı, 2005 - 2010 döneminde ise ortalama $E=0,7 \pm 0,1$ seviyesinde olduğu belirlenmiştir. Ancak beş yıllık periyotlardaki ortalama $E$ değerleri arasında istatistiki olarak fark önemsiz bulunmuştur (one-way ANOVA, $P=$ 0,03976).

\section{M/K oranının değişimi ve $M-K$ ilişkisi}

Doğal ölüm oranının büyüme katsayısına oranı (M/K oranı) 26 çalışma verileri kullanılarak hesaplanmıştır. M/K oranı beş yıllık dönemler halinde değerlendirildiğinde 1,5 değerinin üzerinde olduğu belirlenmiştir (Şekil 12). Beş yıllık periyotlardaki $\mathrm{M} / \mathrm{K}$ oranları arasındaki fark istatistiksel olarak önemsiz bulunmuştur (one-way ANOVA, $P=0,9525$ ). Yine hamsi üzerine şimdiye kadar yapılan 26 çalışma sonuçları değerlendirildiğinde $\mathrm{M}$ ile $\mathrm{K}$ arasındaki regresyon denklemi: $\mathrm{M}$ $=0,7171 \mathrm{~K} 0,3073(\mathrm{r} 2=0,2982 ; n=26 ; \mathrm{P}<0,05)$ şeklinde hesaplanmıştır (Şekil 13). Denklemin regresyon katsayısı sıfırdan istatistiksel olarak farklı bulunmuştur $(P<0,05)$. 

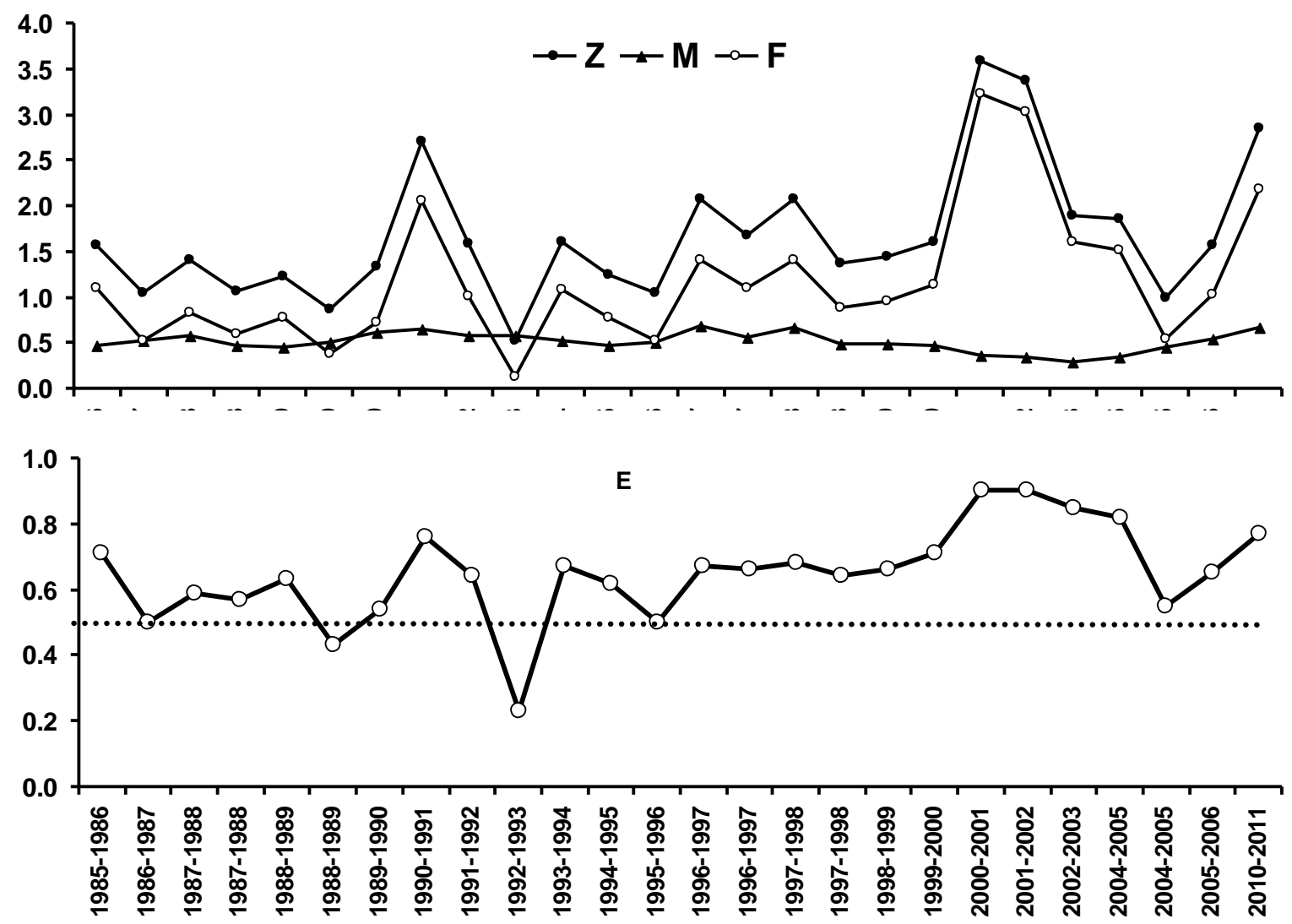

Şekil 10. Türkiye sularında avlanan hamsi balığının ölüm oranları ve işletme oranının av sezonlarına göre değişimi. Z: toplam ölüm oranı (yıl-1), M: doğal ölüm oranı (yıl-1), F: balıkçılık ölüm oranı (yıl-1), E: işletme oranı

Figure 10. Changes of mortality and exploration ratios in fishing seasons of anchovy caught in waters of Turkey. Z: instantaneous mortality ratio (year-1), M: natural mortality ratio (year-1), F: fishing mortality ratio (year-1), E: exploration ratio

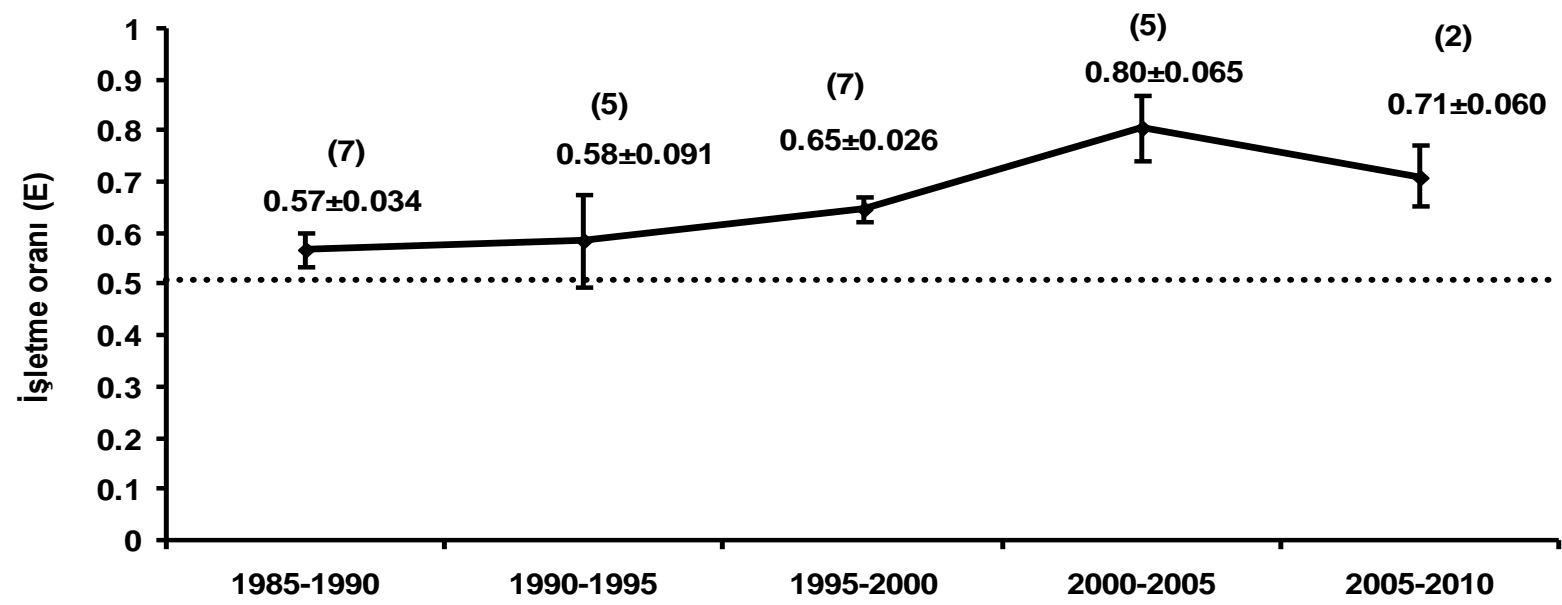

Şekil 11. Türkiye sularında avlanan hamsi balığının işletme oranının beş yıllık dönemlere göre dişimi. Parantez içindeki rakamlar çalışma sayısını göstermektedir Figure 11. Changes of exploration ratios in the five years periods of anchovy caught in waters of Turkey. The numbers in parentheses indicates the number of researches 


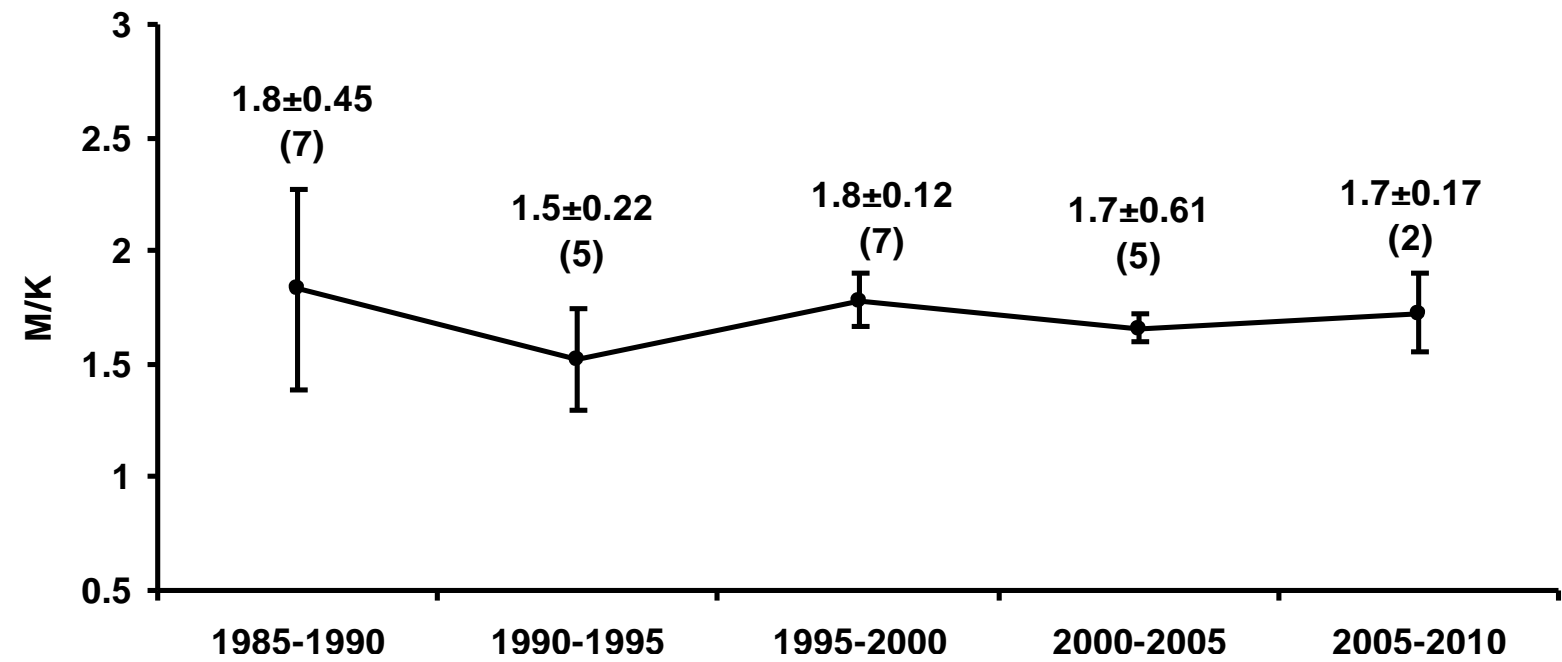

Şekil 12. Türkiye sularında avlanan hamsi balığının doğal ölüm oranı ( $M$, yıl-1) değerinin büyüme katsayısına (K, yıl-1) oranının (M/K oranı) beş ylllık dönemler halinde değişimi. Parantez içindeki rakamlar çalışma sayısını göstermektedir

Figure 12. Changes of the natural mortality/brody growth coefficient ratios in the five years periods of anchovy caught in waters of Turkey. The numbers in parentheses indicates the number of researches

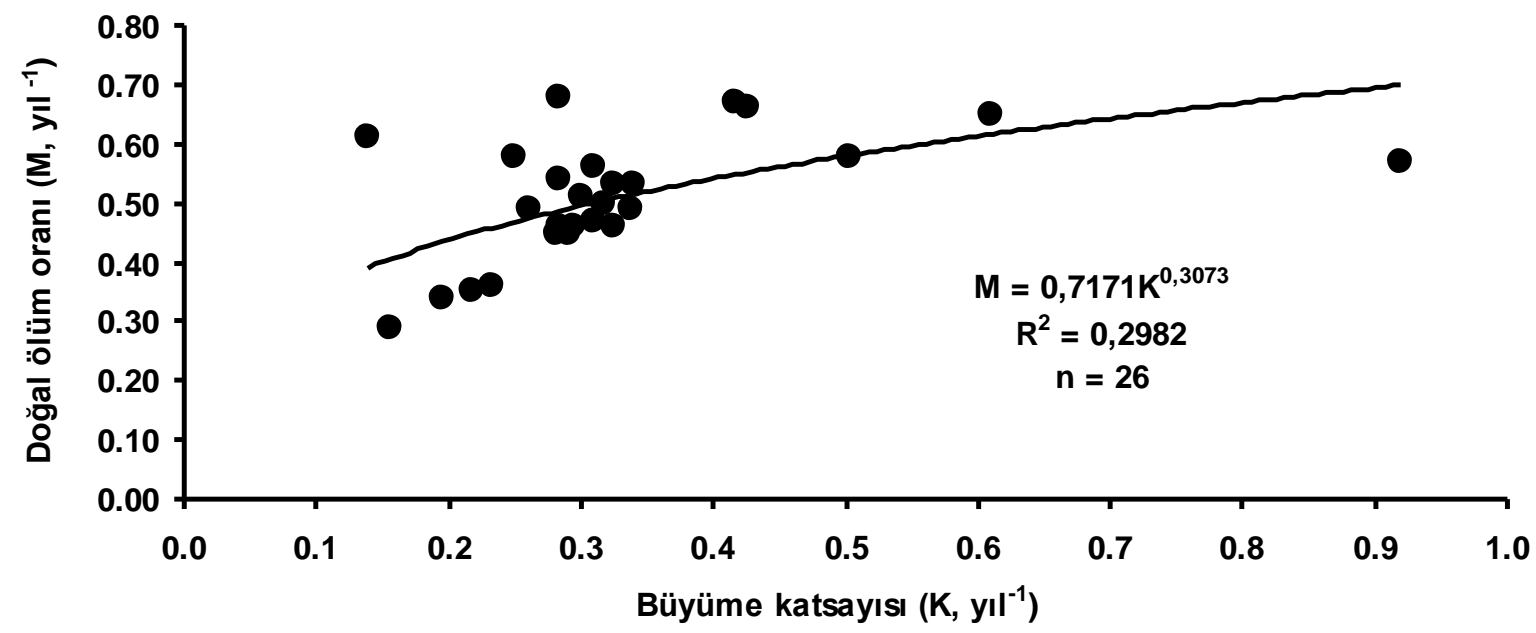

Şekil 13. Türkiye sularında avlanan hamsi balığının doğal ölüm oranı (M) ile büyüme katsayısı (K) arasındaki ilişki

Figure 13. Relationship of between natural mortality ratio $(M)$ and brody growth coefficient $(K)$ of anchovy caught in waters of Turkey

\section{TARTIŞMA VE SONUÇ}

Hamsi av miktarında 1967 yılından günümüze kadar bilinen birçok neden dolayı yıllara göre önemli dalgalanmalar görülmüştür (Şekil 14).

$\mathrm{Bu}$ nedenlerden bazıları av çabasındaki kontrolsüz gelişmeler ve aşırı avcılık, kirlilik, Karadeniz ekosistemini ve hamsi stoklarını etkileyen Minemiopsis leidyi ve Beroe ovata gibi istilacı türlerin Karadeniz'e girmesi (Kideys, 1994; Kideys vd., 1999; Shiganova vd., 2001), hamsinin besinini oluşturan birincil üretimdeki yıllara göre farklılıklar (Bat vd., 2007; Kideys, 1994), deniz suyu sıcaklığında ve tuzluluğundaki yıllara göre farklılıklar, prey - predatör ilişkisi örneğin hamsi üzerinden beslenen ve halen Karadeniz'de popülasyonlarının durumu bilinmeyen üç yunus türünün (Phocoena phocoena, Tursiops truncatus, Delphinus delphis) sayısı (Çelikkale vd., 1988) ve bu yunus türlerinin hamsi üzerinden beslenme alışkanlıklarının boyutu (Birkun, 2002), ayrıca hamsi ile beslenen palamut gibi balıkların Karadeniz ekosistemindeki popülasyon hareketliği ve beslenme alışkanlıklarının hamsi stoklarıyla ilişkisinden (Şahin vd., 2008; Ulman vd., 2013) kaynaklı olabilecek bir çok faktör hamsinin Karadeniz'deki stoklarını etkilemekte ve bu durumdaki dalgalanmalar hamsi av miktarının yıllara göre dalgalanmasına neden olabilmektedir.

Birçok bitki türü, balık, kabuklular ve sürüngen türleri; başta sıcaklık olmak üzere, besin madde miktarı, ışık, üreme aktiviteleri gibi faktörlerin mevsimsel değişimlerinden dolayı 
büyümelerinde farklllık gösterirler (Von Bertalanffy, 1951; Somers, 1988). Büyümedeki bu farklllık mevsimsel büyüme değişimlerini içermeyen von Bertalanffy büyüme denklemine Somers (1988) tarafından 2 parametre [C: büyüme salınım genliği olup, büyümedeki sinusoidal salınımının büyüklüğünü ifade eder $(0<C<1)$. ts: dış bükey büyüme eğrisinin başlangııına denk gelen zaman] daha eklenerek mevsimsel VBBD şeklinde bildirilmiştir. Hamsi, yukarıda değinilen nedenlerden dolayı büyümede mevsimsel değişim gösteren bir balıktır. Bu mevsimsel büyüme özelliği hamsi için hesaplanmış ve şekil 15'de gösterilmiştir. Hamsinin büyümesi özellikle deniz suyu sıcaklığının düşük olduğu şubat - nisan ayları arasında yavaşlamaktadır. Bu durum hamsinin beslenme alışkanlıkları ve besin madde miktarılla ilişkili olabilir (Bilgin vd., 2013). Bilgin vd. (2013) tarafindan rapor edilen mevsimsel VBBD parametreleri Taylor (1958) tarafından önerilen formüle uygulandığında hamsinin maksimum yaşı 3,51 yıl olarak hesaplanmıştır (Şekil 15).

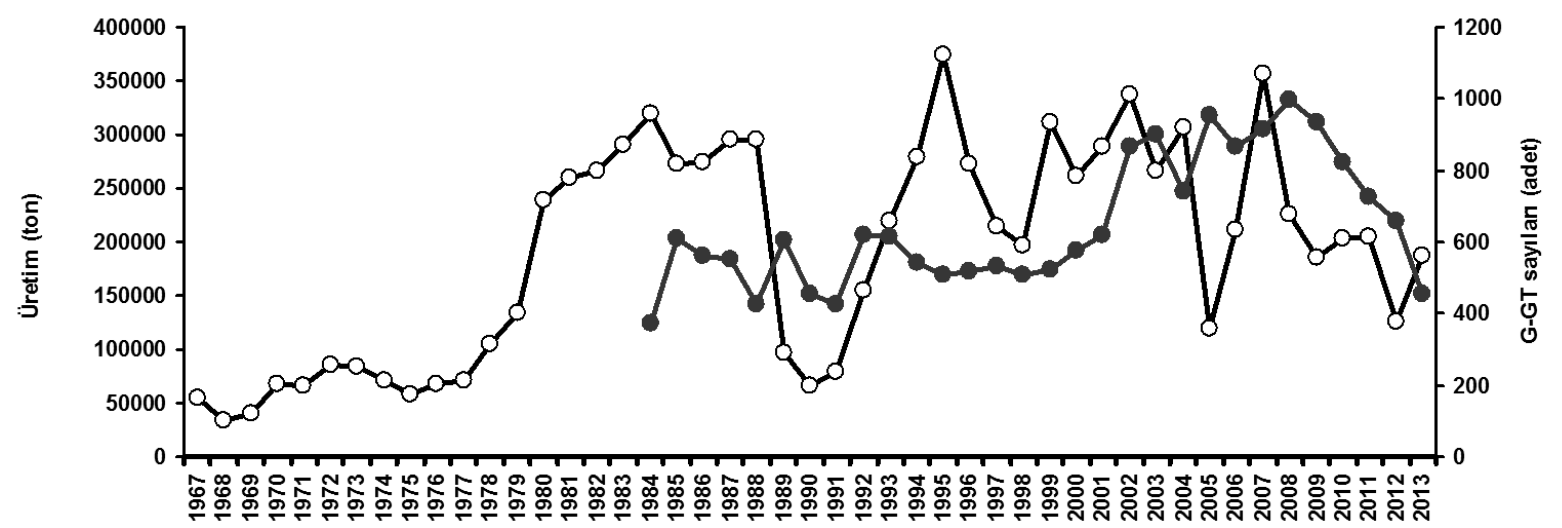

Şekil 14. Yıllara göre avcılık yoluyla üretilen hamsi miktarı ve gırgır (G) ve Gırgır trol (GT) tekne sayıları. Veriler TUiK tarafından yayınlanan 1967- 2013 periyodundaki dönemi kapsamaktadır (TUIK, 2013)

Figure 14. The amount of anchovy catches and number of purse seine (PS) and purse seine - trawl (PS-T) by years. The data covers the period $1967-2013$ published by the TSI

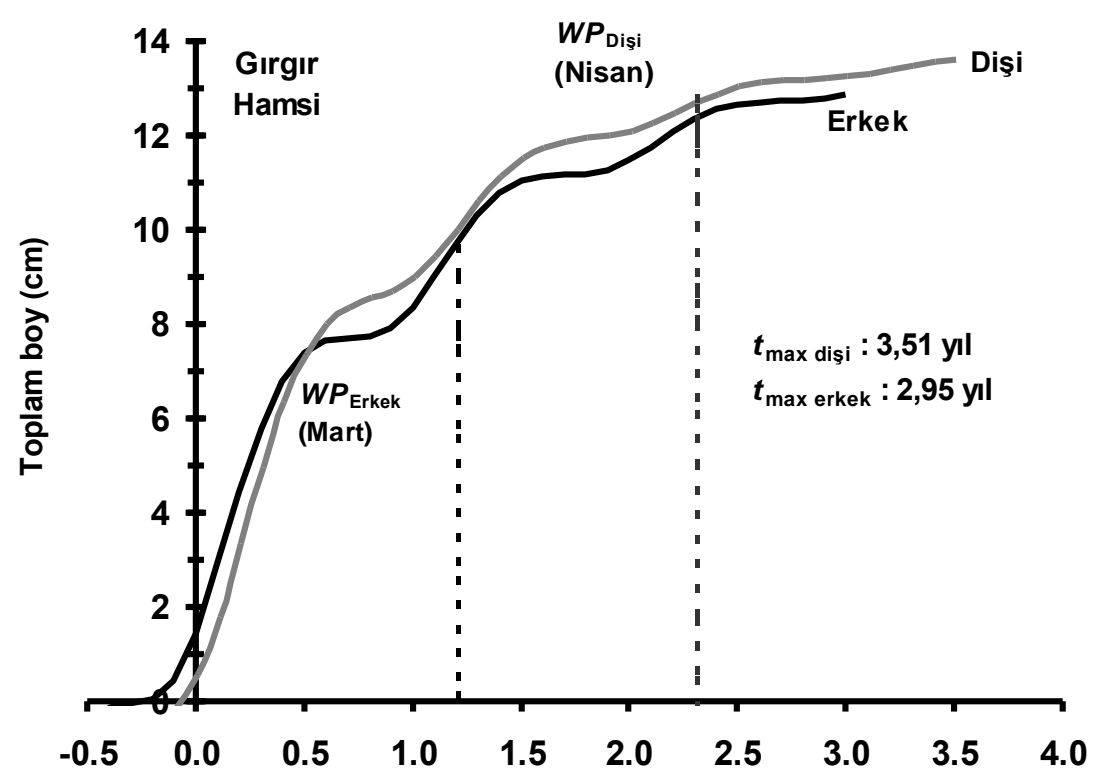

Yaş (yıl) 


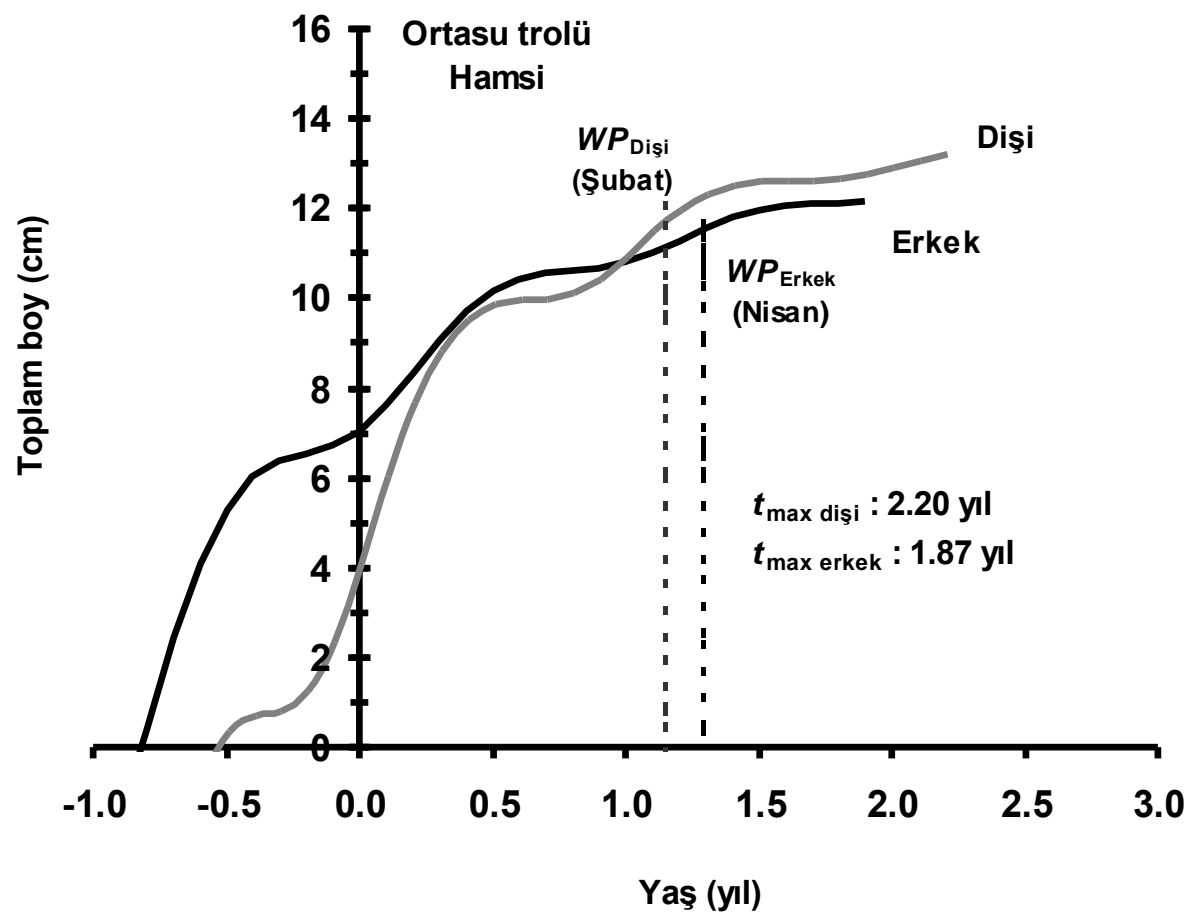

Şekil 15. Karadeniz'de gırgır ve ortasu trolü ile avlanan hamsi için cinsiyetlere göre hesaplanan sezonsal von Bertalanffy büyüme denklemi eğrisi grafiği. Şekillerin çizilmesinde Bilgin vd. (2013) tarafından yayınlanan makalenin bulguları kullanıımıştır. WP: kış noktası. Maksimum yaşın hesaplanmasında formülü (Taylor, 1958) kullanılmıştır

Figure 15. The seasonal von Bertalanffy growth function curve graphs by sexes of anchovy caught by purse seine and mid-water trawl in the Black Sea. WP: winter point. The results of the article published by Bilgin et al. (2013) is used for drawing figures. equation (Taylor, 1958) is used for calculation of the maximum age

Hamsi balığı için hesaplanan $\mathrm{K}$ değerleri av sezonlarına göre değişim göstermektedir. Hesaplanan en büyük K değeri 1987 - 1988 av sezonunda Düzgüneş ve Karaçam (1989) tarafından rapor edilen 0,92 yıl-1 dır. 2010 - 2011 av sezonunda Karadeniz'de yapılan bir çalışmada (Bilgin vd., 2013) ise dişilerin $\mathrm{K}$ değerinin 1,25 yll-1 ve erkeklerin ise $\mathrm{K}$ değerinin 0,99 yıl-1 olduğu rapor edilmiş ve 1987 - 1988 av sezonundan sonra en yüksek K değerinin 2010 - 2011 av sezonunda hesaplandığı görülmüştür. Yani, hamsi balığı hızlı büyüme özelliği göstermekte ancak büyüme hızında av sezonlarına göre dalgalanmalar olmaktadır.

Çalışmaların sonuçlarına göre, Karadeniz'de avlanan hamsi balığının yaş kompozisyonunda av sezonlarına göre dalgalanmaların olduğu görülmektedir. Çalışma sonuçlarına göre, hamsi avcılığının özellikle 1 yaşındaki bireylerin üzerinde yoğunlaştığı (\%42), avlanan balıkların kompozisyonunu bir yaşındaki bireylerden sonra sıfır yaş (\%27), iki yaş (\%25) ve az miktarda da üç yaşındaki (\%6) balıkların oluşturduğu tespit edilmiştir. Burada sıfır yaşındaki bireylerin av miktarının fazlalığından söz edilebilir. Çünkü yukarıda da değinildiği gibi hamsi bir yaşına kadar neredeyse büyüye bileceği boyun yaklaşık \%60 - 70'lik kısmını (Şekil 8) sıfır yaş döneminde büyümekte ve bu balıkların $\% 25$ civarında avlandığı düşünülürse ekonomik ve ekolojik anlamda büyümeleri devam ettiği halde avlanıyor yani büyümede aşırı avcılık yapılıyor anlamına gelmektedir. Bu durumda ekonomik kayıplardan söz edilebilir.

Av sezonlarına göre hamsi üzerine yapılmış çalışmalar değerlendirildiğinde, bir yaşındaki bireylerin ortalama boy değerlerinin $L \infty$ değerine ulaşma oranı yaklaşık $\% 60$, Lmaximum boy değerine ulaşma oranı ise yaklaşık $\% 70$ civarındadır (Şekil 8). Çevresel parametreler özellikle sıcaklık ve klorofil-a konsantrasyonu ile buna bağlı olarak hamsinin besinini oluşturan birincil üretimin yoğunluğu (Ağırbaş vd., 2010) ve üreme faaliyetleri süresince büyümeden ziyade gonad gelişimi için enerji harcanması büyümeyi etkileyen önemli faktörlerdir. Bir yaşına kadar hamsi'nin büyümesi hızlı olmakta ve 1 yaşından sonra büyüme azalmaktadır. Bu durum muhtemelen cinsel olgunluğa ulaşmasından kaynaklanmaktadır. Karadeniz'de hamsi bir yaşında cinsel olgunluğa ulaşmaktadır (Erkoyuncu ve Özdamar, 1989). Karadeniz ekosistemindeki hamsi balığının biyolojik özellikleri üzerine yapılan bir araştırmada, hamsinin $\% 50$ cinsi olgunluk

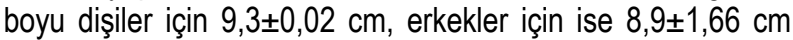
olarak rapor edilmiştir (Kayalı, 1998). Yani bir yaşındaki balıkların ortalama boyları da boy yasağı olan $9 \mathrm{~cm}$ civarında olup uygulanan boy yasağının biyolojik açıdan uygun olduğu düşünülmektedir. 
Balık popülasyonlarında $M / K$ oranı önemlidir. Hızlı büyüyen balıklarda $\mathrm{K}$ ile $\mathrm{M}$ değerleri yüksek olmakta, yavaş büyüyen balıklarda ise düşük olmaktadır. Erkoyuncu (1995)'ya göre M/K oranı 0,5 gibi düşükse az avlanma ile balığın büyümesi beklenmeli, $M / K$ oranı 5,0 gibi yüksekse maksimum ürün elde etmek için ilk avlama boyu küçük olacak şekilde mümkün olduğunca çabuk avlamak gerekir. Bu değer çoğu balık türü için 0,8 ile 2,2 arasında rapor edilmiştir (Erkoyuncu, 1995). Hamsi için yapılan 26 çalışmada $\mathrm{M} / \mathrm{K}$ oranı $0,6-2,4$ arasında (ortalama: $1,6 \pm 0,07$ ) hesaplanmıştır. Hamsinin M/K değeri bir çok balık türü için rapor edilen 0,8-2,2 arasında olup, ortalama $M / K$ değerine göre hamsinin avlanma hızının normal değerler arasında olduğu söylenebilir.

Geçmişten günümüze yapılan çalışmaların sonuçlarına göre, Karadeniz'de avlanan hamsi balığının yıllık ölüm oranlarını, balıkçılık ölüm oranlarının arttırdığı rahatıkla söylenebilir (Şekil 10). Ayrıca işletme oranının (E) beş yıllık dönemlerdeki sonuçları incelendiğinde, işletme oranı değerinin 1985 - 1990 döneminden 2000 - 2005 dönemine kadar sürekli bir artış gösterdiği ve çalışma sonuçlarına göre işletme oranının da optimum değerin üzerinde olduğu görülmüştür. Sürdürülebilir bir balıkçlık için işletme oranının 0,5 seviyesinde olması gerekmektedir. Diğer bir ifadeyle avclık ölüm oranının doğal ölüm oranına eşit olduğu ( $M=F$ ) bir şekilde avclık yapıldığında hamsi stoklarının optimum bir şekilde işletilebileceği söylenebilir.

Avlanabilir asgari boyu $9 \mathrm{~cm}$ olan hamsi için ağırlıkça \% 15 oranında küçük boylara istisna tanınmaktadır (Anonim, 2012). Hamsinin mevcut $9 \mathrm{~cm}$ boy yasağı $\% 50$ cinsi olgunluk boyu ile uyumlu olup, büyümede aşırı avcılığı azaltmak, ekolojik ve ekonomik hamsi avcılığını sağlayabilmek için avlanan sıfır yaşındaki balıkların oranının (bu oran yaklaşık \%30 civarındadır) azaltıımasının hamsi balıkçıık yönetimi açısından uygun olacağı düşünülmektedir. Ayrıca ortalama işletme oranının (E) $0,7 \pm 0,03$ olduğu hamsi stokunu daha verimli bir hale getirmek için işletme oranının 0,5 düzeyine yakın olması

\section{KAYNAKÇA}

Ağırbaş, E., Seyhan, K., Kasapoğlu, N., Feyzioğlu, M., Üstündağ, E., \& Eruz, C. (2010). Recent changes of the Turkish anchovy fishery in the black sea with special reference to climate change. Journal of Environmental Protection and Ecology, 11(4): 1495 - 1503

Akoğlu, E. (2013). Nonlinear dynamics of the Black Sea ecosystem and its response to anthropogenic and climate variations. $\mathrm{PhD}$ thesis, Marine Biology and Fisheries Middle East Technical University Institute of Marine Sciences, Mersin, Turkey, $126 \mathrm{pp}$.

Anonim, (2012). Notification No. 3/1 regulating commercial fisheries. Ministry of Food, Agriculture and Livestock, Fisheries and Aquaculture Directorate General. SUR-COOP Fisheries Central Cooperative Association, Positive Printing, Ankara, $112 p$

Avşar, D. (2005). Fisheries biology and population dynamics. Adana: Nobe press.

Bat, L., Şahin, F., Satımış, H.H., Üstün, F., Birinci-Özdemir, Z., Kıdeys, A.E. \& Shulman, G.E. (2007). The changed ecosystem of the black sea and its impact on anchovy fisheries (in Turkish with English abstract). Journal of FisheriesSciences.com, 1(4):191-227. doi: 10.3153/jfscom.2007024 gerekmektedir. Bunun için mevcut avlama ölüm oranının (F) azaltılması gerektiği düşünülmektedir.

Hamsi küçük pelajik olup, kısa ömürlü, eşeysel verimliliği yüksek, 5-6 ay boyunca 2-3 günde bir yumurtlayan, hızlı büyüyen, çevresel faktörlerden çabuk etkilenen ve Karadeniz'de av baskısı altında olan bir balıktır. Karadeniz'de kııısı olan ülkelerle ortak çalışmalar yapılarak, Karadeniz'deki hamsi stoklarını etkileyen biyotik ve abiyotik faktörlerdeki değişiklikler izlenmeli ve bu değişikliklerin hamsi balıkçlığına etkisi araştııımalıdır. Ayrıca hamsi stokunun devamlılığı ve en yüksek ürün elde etmek için yıllık av miktarı ve av çabası kontrol alıına alınmalı, hamsi stok belirleme çalışmaları neticesinde kota uygulamasına geçilerek Karadeniz'de hamsi balıkçılık yönetim sisteminin oluşturulması önerilmektedir (Chashchin, 1996; Prodanov vd., 1997; Öztürk ve Öztürk, 2005; Bingel ve Gücü, 2010; Öztürk vd., 2011, GFCM, 2013). Karadeniz'deki palamut, lüfer, hamsi, çaça ve istavrit gibi pelajik balık türleriyle beraber kalkan, mezgit ve barbunya gibi demersal balık stoklarının değişen iklim koşulları altında gelecekteki durumunu belirleyecek olan en önemli etkenin balıkçlık baskısı olduğu rapor edilmiştir (Akoğlu, 2013). Ayrıca, Hamsi gibi korunması hedeflenen balık türleri üzerindeki balıkçılık ölüm oranının azaltıımasının yanı sıra, bu türler ile besin ağında sıkı ilişkiler içerisinde olan diğer türlerin izlenmesi ve stoklarının yönetimi gelecekte balık stoklarının sürdürülebilir bir şekilde kullanılabilmesinin en verimli yolu olacağı rapor edilmiştir (Akoğlu, 2013).

\section{TEŞEKKÜR}

Bu çalışma Trabzon Su Ürünleri Merkez Araştırma Enstitüsü tarafından 15-16 Mayıs 2015 tarihinde düzenlenen 3. Ulusal Hamsi Çalıştayı'nda sözlü olarak sunulmuştur.

Bilgin, S. (2006). Evaluated of anchovy, Engraulis encrasicolus (L., 1758), fishing (1985-2005 fishing seasons) Turkish coast (Black Sea) in respect to fisheries biology (in Turkish with English abstract). Erciyes University, Journal of Science and Technology, 22(1 - 2): 213-222.

Bilgin, S., Samsun, N., Samsun, O., \& Kalaycı, F. (2006). Estimation of population parameters of anchovy, Engraulis encrasicolus L. 1758, at 2004-2005 fishing season in the Middle Black Sea, using length frequency analysis methods (in Turkish with English abstract). Ege Journal of Fisheries and Aquatic Sciences, 23(1/3): 359 - 364.

Bilgin, S., Taşçı, B., \& Bal, H. (2013). Sexual seasonal growth of the European anchovy (Engraulis encrasicolus) caught by mid-water trawl and purse seine in the southern Black Sea. Journal of the Marine Biological Association of the United Kingdom, 93(2): 333 - 339. doi:10.1017/S0025315412000732

Bingel, F., \& Gücü, A.C. (2010). Black Sea anchovy and stock (determination) studies. In O. Ak, M. Dağtekin (Eds)., National Workshop on Anchovy, Sustainable Fishing Workshop 2010 (pp. 38-57). Trabzon, Turkey: Proceedings Book. 
Birkun A., Jr. (2002). Interactions between cetaceans and fisheries in the Black Sea. In: G. Notarbartolo di Sciara (Ed.), Cetaceans of the Mediterranean and Black Seas: state of knowledge and conservation strategies. A report to the ACCOBAMS Secretariat, 2002 (pp. 11), Section 10. Monaco.

Chashchin, A.K. (1996). The Black Sea populations of anchovy. Scientia Marina, 60 (Supl. 2): 219 - 225.

Çelikkale, M.S., Ünsal, S., Durukanoğlu, H.F., Karaçam, H., Düzgüneş, E., Okumuş, I., Seyhan, K., Özmen, G., Dinçer, A.C., Özer, N.P., Köse, S. Kılıç, C., Demirel, \& O., Candeğer, A.F. (1988). Determination of biology and stock of dolphin species in the Black Sea (in Turkish with English abstract). Ministry of food, agriculture and livestock, No: D.S.86.101.010.1, $80 \mathrm{pp}$

Düzgüneş, E., \& Karaçam, H. (1989). Investigation of some population parameters and growth caharacteristics of anchovy (Engraulis encrasicolus L., 1758) in the Black Sea (in Turkish with English abstract). Doğa, Turk Zooloji D.C., 13(2): 77 - 83.

Erkoyuncu, İ. (1995). Fisheries biology and population dynamics, Samsun: Ondokuz Mayıs Üniversitesi Press.

Erkoyuncu, İ., \& Özdamar, E. (1989). Estimation of the age, size and sex composition and growth parameters of Anchovy Engraulis encrasicolus $(\mathrm{L})$ in the Black Sea. Fisheries Research, (7): 41-247.

Genç, Y., Ak, O., Başçınar, N.S., Dağtekin, M., Erbay, M., \& Atılgan, E. (2010) Non-target catch rates and population parameters of anchovy (Engraulis encrasicolus (L., 1758)) caught 2009 - 2010 fishing season in the Eastern Black Sea (in Turkish with English abstract). In O. Ak, M. Dağtekin (Eds). National Workshop on Anchovy, Sustainable Fishing Workshop 2010 (pp. 58-64). Trabzon, Turkey: Proceedings Book.

GFCM, (2013). Joint GFCM-BSC Workshop on IUU fishing in the Black Sea. BSC Headquarters 2013 (58 p), Istanbul, Turkey.

Gözler, A.M., \& Çiloğlu, E. (1998). A study on some population parameters of anchovy (Engraulis encrasicolus L., 1758) caught 1997- 1998 fishing season off Rize-Hopa (in Turkish with English abstract). Eastern Anatolia Region III. Symposium on Fisheries 1998 (pp. 373-382). Erzurum, Turkey. Proceedings Book

Hammer, Ø., Harper, D.A.T., \& Ryan, P.D. (2001). PAST: Paleontological Statistics Software Package for Education and Data Analysis. Palaeontologia Electronica, 4: 9 .

Karaçam, H., \& Düzgüneş, E. (1990). Age, growth and meat yield of European Anchovy (Engraulis encrasicolus L.,1758) in the Black Sea. Fisheries Research, 9(2): 181-186

Kayalı, E. (1998). A study on the biological characteristics of anchovy (Engraulis encrasicolus, L., 1758) and horse mackerel (Trachurus mediterranues) in the Eastern Black Sea ecosystem. M.Sc Thesis, Black Sea Technical University, Institute of Science and Technology, Department of Fisheries Technology Engineering, 238 p, Trabzon, Turkey.

Kideys, A.E. (1994). Recent dramatic changes in the Black Sea ecosystem: The reason for the sharp decrease in Turkish anchovy fisheries. Journal of Marine Systems, 5: 171-181. doi: 10.1016/0924-7963(94)90030-2

Kideys, A.E., Gordina, A.D., Bingel, F., \& Niermann, U. (1999). The effect of environmental conditions on the distribution of eggs and larvae of anchovy (Engraulis encrasicolus, L.) in the Black Sea. ICES Journal of Marine Science, 56: 58-64. doi: 10.1006/jmsc.1999.0605

Lisovenko, L.A., \& Andrianov, D.P. (1996). Reproductive biology of anchovy (Engraulis encrasicolus ponticus Alexandrov 1927) in the Black Sea. Scientia Marina, 60 (2): 209 - 218.

Mutlu, C. (1994). A study on the some population characteristics of anchovy (Engraulis encrasicolus, L., 1758) in the Eastern Black Sea. M.Sc Thesis, Black Sea Technical University, Institute of Science and Technology, Department of Fisheries Technology Engineering, 44 p, Trabzon, Turkey.

Mutlu, C. (2000). population characteristics and implementation of analytical methods for the prediction of the stock quantity of anchovy (Engraulis encrasicolus Linnaeus, 1758) in the Eastern Black Sea. PhD Thesis, Black Sea Technical University, Institute of Science and Technology, Department of Fisheries Technology Engineering, 112 p, Trabzon, Turkey.

Özdamar, E., Khiara, K., Sakuramato, K., \& Erkoyuncu, İ. (1994). Variation in the population structure of European Anchovy, Engraulis encrasicolus L. L. in The Black Sea. Journal of Tokyo University of Fisheries, 81(2): 123134.
Özdamar, E., Samsun, O., \& Erkoyuncu, İ. (1995). Estimation of population parameter of anchovy (Engraulis encrasicolus L.) caught 1994-1995 fishing season in the Black Sea (in Turkish with English abstract). Ege Journal of Fisheries and Aquatic Sciences, 12(1-2): 135 - 144

Öztürk. B., \& Öztürk, A.A., (2005). Biodiversity of the Black Sea: The threat and the future. In: N. Miyazaki, Z. Adel, K. Ohwada (eds.) Mankind and Oceans. United Nation University Press, 2005 (pp. 155-171). Tokyo, Japan: Proceedings Book.

Öztürk, B., Keskin, C., \& Engin, S. (2011). Some remarks on the catches of anchovy, Engraulis encrasicolus (Linnaeus, 1758), in Georgian waters by Turkish fleet between 2003 and 2009. J. Black Sea/Mediterranean Environment, 17(2): 145-158.

Prodanov, K., Mikhailov, K., Daskalov, G., Maxim, C., Chashchin, A., Arkhipov, A., Shlyakhov, V., \& Ozdamar, E. (1997). Environmental management of fish resources in the Black Sea and their rational exploitation. Studies and Reviews. General Fisheries Council for the Mediterranean, No: 68, Rome, $\mathrm{FAO}, 178 \mathrm{p}$.

Sağlam, N.E., \& Sağlam, C. (2013). Age, growth and mortality of anchovy Engraulis encrasicolus in the south-eastern region of the Black Sea during the 2010-2011 fishing season. Journal of the Marine Biological Association of the United Kingdom, 93: 2247-2255 doi:10.1017/S0025315413000611

Samsun, O., Samsun, N., \& Karamollaoğlu, A.C. (2004). Age, growth and mortality rates of the European anchovy (Engraulis encrasicolus L. 1758) in the Turkish Black Sea Coast. Turkish Journal of Veterinary and Animal Sciences, 28(5): $901-910$.

Samsun, O., Samsun, N., Kalayci, F., \& Bilgin, S. (2006). A study on recent variations in the population structure of European anchovy (Engraulis encrasicolus L., 1758) in the Southern Black Sea. Ege Journal of Fisheries and Aquatic Sciences, 23(3-4): $301-306$.

Satilmis, H.H., Gordina, A.D., Bat, L., Bircan, R., Culha, M., Akbulut, M., \& Kideys, A.E. (2003). Seasonal distribution of fish eggs and larvae off sinop (the southern Black Sea) in 1999-2000. Acta Oecologica, 24: S275-S280.

Shiganova, T.A., Mirzoyan, Z.A., Studenikina, E.A., Volovik, S.P., SiokouFrangou, I., Zervoudaki, S., Christou, E.D., Skirta, A.Y., \& Dumont, H.J. (2001). Population development of the invader ctenopore Mnemiopsis leidyi, in the Black Sea and in other seas of the Mediterranean basin. Marine Biology, 139: 431-445. doi: 10.1007/s002270100554

Slastenenko, E. (1955-1956). Black Sea basin fish. İstanbul: Meat and Fish Authority General Directorate Press.

Somers, I.F. (1988). On a seasonally oscillating growth function. Fishbyte, 6(1): $8-11$.

Snedecor, G.W \& Cochran, W.G. (1989). Statistical methods, lowa: lowa State University Press.

Şahin, C., Akın, Ş., Hacımurtazaoğlu, N., Mutlu, C., \& Verep, B. (2008). The stock parameter of anchovy (Engraulis encrasicolus) population on the coasts of the eastern Black Sea: reason and implications in declining of anchovy population during the $2004-2005$ and 2005 - 2006 fishing seasons. Fresenius Environmental Bulletin, 17(12b): 2159 - 2169.

Taylor, C.C. (1958). Cod growth and temperature. J.Cons. int. Explor. Mer, 23(3): $366-370$.

TUIK (2013). Turkey Fisheries Statistics. https://biruni.tuik.gov.tr/medas/ (09.02.2016)

Ulman, A., Bekişoğlu, Ş., Zengin, M., Kunudsev, S., Ünal, V., Mathews, C., Harper, S., Zeller, D., \& Pauly, D. (2013). From bonito to anchovy: a reconstruction of Turkey's marine fisheries catches (1950-2010). Mediterranean Marine Science, 14 (2): 309-342. doi: 10.12681/mms.414

Ünsal, N. (1989). Determination of small landing size and age - length - weight relationships of anchovy, Engraulis encrasicolus (L. 1758) in the Black Sea (in Turkish with English abstract). Istanbul University Journal of Fisheries, 3(1-2): $17-28$.

Von Bertalanffy, L. (1951). Metabolic types and growth types. The American Naturalist, LXXXV 821, 111-117.Løkkeborg, S. \& Pina, T. (1997). Effects of setting time setting direction and soak time on longline catch rates. Fisheries Research, 32 (1): 213-222. doi: 10.1016/S0165-7836(97)00070-2 